\title{
Enhanced extinction of visible radiation due to hydrated aerosols in mist and fog
}

\author{
T. Elias ${ }^{1}$, J.-C. Dupont ${ }^{2}$, E. Hammer ${ }^{3, *}$, C. R. Hoyle ${ }^{3,{ }^{* *}}$, M. Haeffelin ${ }^{2}$, F. Burnet ${ }^{4}$, and D. Jolivet ${ }^{1}$ \\ ${ }^{1}$ HYGEOS, Euratechnologies, 59000 Lille, France \\ ${ }^{2}$ Institut Pierre Simon Laplace, 91128 Palaiseau, France \\ ${ }^{3}$ Laboratory of Atmospheric Chemistry, Paul Scherrer Institut, 5232 Villigen-PSI, Switzerland \\ ${ }^{4}$ Centre National de Recherche Météorologique, 31057 Toulouse, France \\ *now at: Grolimund + Partner Ltd - environmental Engineering, Thunstrasse 101A, 3006 Bern, Switzerland \\ ** now at: Swiss Federal Institute for Forest Snow and Landscape Research (WSL)-Institute for Snow and Avalanche Research \\ (SLF), 7270 Davos, Switzerland
}

Correspondence to: T. Elias (te@ hygeos.com)

Received: 19 September 2014 - Published in Atmos. Chem. Phys. Discuss.: 7 January 2015

Revised: 4 May 2015 - Accepted: 10 May 2015 - Published: 16 June 2015

\begin{abstract}
The study assesses the contribution of aerosols to the extinction of visible radiation in the mist-fog-mist cycle. Relative humidity is large in the mist-fog-mist cycle, and aerosols most efficient in interacting with visible radiation are hydrated and compose the accumulation mode. Measurements of the microphysical and optical properties of these hydrated aerosols with diameters larger than $0.4 \mu \mathrm{m}$ were carried out near Paris, during November 2011, under ambient conditions. Eleven mist-fog-mist cycles were observed, with a cumulated fog duration of $96 \mathrm{~h}$, and a cumulated mist-fogmist cycle duration of $240 \mathrm{~h}$.

In mist, aerosols grew by taking up water at relative humidities larger than $93 \%$, causing a visibility decrease below $5 \mathrm{~km}$. While visibility decreased down from 5 to a few kilometres, the mean size of the hydrated aerosols increased, and their number concentration $\left(N_{\text {ha }}\right)$ increased from approximately 160 to approximately $600 \mathrm{~cm}^{-3}$. When fog formed, droplets became the strongest contributors to visible radiation extinction, and liquid water content (LWC) increased beyond $7 \mathrm{mg} \mathrm{m}^{-3}$. Hydrated aerosols of the accumulation mode co-existed with droplets, as interstitial non-activated aerosols. Their size continued to increase, and some aerosols achieved diameters larger than $2.5 \mu \mathrm{m}$. The mean transition diameter between the aerosol accumulation mode and the small droplet mode was $4.0 \pm 1.1 \mu \mathrm{m}$. $N_{\mathrm{ha}}$ also increased on average by $60 \%$ after fog formation. Consequently, the mean contribution to extinction in fog was $20 \pm 15 \%$ from hy-
\end{abstract}

drated aerosols smaller than $2.5 \mu \mathrm{m}$ and $6 \pm 7 \%$ from larger aerosols. The standard deviation was large because of the large variability of $N_{\text {ha }}$ in fog, which could be smaller than in mist or 3 times larger.

The particle extinction coefficient in fog can be computed as the sum of a droplet component and an aerosol component, which can be approximated by $3.5 N_{\mathrm{ha}}\left(N_{\mathrm{ha}}\right.$ in $\mathrm{cm}^{-3}$ and particle extinction coefficient in $\mathrm{Mm}^{-1}$ ). We observed an influence of the main formation process on $N_{\text {ha }}$, but not on the contribution to fog extinction by aerosols. Indeed, in fogs formed by stratus lowering (STL), the mean $N_{\text {ha }}$ was $360 \pm 140 \mathrm{~cm}^{-3}$, close to the value observed in mist, while in fogs formed by nocturnal radiative cooling (RAD) under cloud-free sky, the mean $N_{\text {ha }}$ was $600 \pm 350 \mathrm{~cm}^{-3}$. But because visibility (extinction) in fog was also lower (larger) in RAD than in STL fogs, the contribution by aerosols to extinction depended little on the fog formation process. Similarly, the proportion of hydrated aerosols over all aerosols (dry and hydrated) did not depend on the fog formation process.

Measurements showed that visibility in RAD fogs was smaller than in STL fogs due to three factors: (1) LWC was larger in RAD than in STL fogs, (2) droplets were smaller, (3) hydrated aerosols composing the accumulation mode were more numerous. 


\section{Introduction}

Aerosols and droplets strongly influence the Earth's radiative budget: clouds increase the Earth's albedo (Boucher et al., 2013), and aerosol particles may partly counteract global warming by greenhouse gases (Anderson et al., 2003). They are also responsible for critical reductions of atmospheric visibility at the surface level during the fog formation, with important consequences for transportation activities (Rosenfeld, 1996).

Aerosol particles and fog droplets are responsible for the reduction of visibility by scattering and absorbing light, according to their number and properties, such as size, shape, and chemical composition. Atmospheric humidity is a major factor affecting the particle properties, as aerosols can grow by the uptake of water (e.g. Winkler, 1988), when relative humidity increases. Consequently, under conditions of relative humidity larger than $95 \%$, the aerosol radiative forcing can increase by $60 \%$ (Adams et al., 1999), and atmospheric visibility can be critically reduced (e.g. Chen et al., 2012). At relative humidities larger than $100 \%$, water condenses on some aerosols which are activated, and form fog droplets (e.g. Jiusto, 1981). The sudden increase in particle size causes a sharp drop in visibility (Elias et al., 2009), usually to distances below $1 \mathrm{~km}$. In addition to these droplets, fog also contains interstitial non-activated aerosols, which have a critical supersaturation (Köhler et al., 1937) larger than the peak supersaturation (Hammer et al., 2014a) and grow to their stable equilibrium size by taking up water, but do not activate to form droplets.

Numerical weather predictions of fog formation, development and dissipation usually neglect the various aerosol radiative effects, which are

1. reduction of the solar radiation reaching the surface, with potential influences on late afternoon cooling before fog formation, and on a fog dissipation delay in the morning;

2. impact on the radiative cooling in the nocturnal boundary layer (Mukund et al., 2014);

3. influence on the droplet optical properties, by acting as cloud condensation nuclei $(\mathrm{CCN})$.

Moreover, visibility is usually parameterised based on droplet properties uniquely (e.g. Gultepe et al., 2006; Stolaki et al., 2014). However, Jiusto (1981) suggested that a significant amount of the total extinction in fog is due to hydrated aerosol particles of the accumulation mode (with diameters smaller than 2 to $4 \mu \mathrm{m}$ ), which were shown by Eldridge (1966) to be predominant in number. It was shown by Elias et al. (2009) that such aerosols could contribute up to $25 \%$ of the extinction of visible radiation in a fog formed under urban influence.

The current work addresses the contribution of this hydrated aerosol to extinction, and its variability. In the frame- work of the PreViBOSS project, observation of microphysical properties of droplets and aerosols was performed during three 6-month fog seasons at SIRTA (Site Instrumental de Recherche par Télédétection de l'Atmosphère, which is French for Instrumented Site for Atmospheric Remote Sensing Research) (Haeffelin et al., 2005). SIRTA is a platform where other measurements are routinely made, for atmospheric vertical profiling, and sounding of dynamic, thermodynamic, and radiative properties. We processed the SIRTA database to make connections between (1) aerosol properties; (2) fog properties (visibility and droplet number concentration); and (3) atmospheric processes responsible for fog formation: nocturnal radiative cooling or stratus lowering.

Two particle counters measured the microphysical properties of particles in mist and fog, during 1 month, under ambient conditions, while visibility varied by a factor of 50 . Independent measurements of visibility gave the opportunity to validate both mist and fog size distributions, based on Mie theory. Air samples were deliberately not heated, in order to observe the influence of relative humidity on the optical extinction caused by hydrated aerosol, without having to make assumptions about aerosol hygroscopicity. Moreover, direct measurements were made of both fog droplet and interstitial non-activated aerosol properties, with no need for an inlet system to separate both, and no need for assumptions regarding the limiting diameter between aerosols and droplets.

Data and methods are presented in Sect. 2. Independent measurements of particle microphysical and optical properties were performed (Sect. 2.1). Mie theory was applied to compute the particle extinction coefficient, inversely proportional to visibility, from measured size distributions. Observed size distributions in fog were approximated by multimodal log-normal distributions, allowing the discrimination between aerosols and droplets and allowing the estimation of the impact of hydrated aerosols with diameters larger than $2.5 \mu \mathrm{m}$. The methodology is presented in Sect. 2.2. It is important to distinguish fog from mist, where droplet contribution to extinction is negligible. The distinction was based on observed liquid water content (LWC), which is mainly affected by droplets (Sect. 3). Results are presented in Sect. 4. First, a closure study was performed to validate the methodology and to check the data set consistency (Sect. 4.1). Observations were analysed to estimate the mean contribution of hydrated aerosols to extinction of radiation in fog (Sect. 4.2), and their microphysical and optical properties (Sect. 4.3), that we related to the fog formation type (Sect. 4.4). Conclusions are given in Sect. 5.

\section{Data and methods}

\subsection{Measurements}

We analysed data acquired in November 2011, when the instrument set-up was optimal. Moreover, November is the 
most favourable month for mist and fog formation at SIRTA, due to high humidity conditions: around $80 \%$ of observed relative humidity (RH) was larger than $90 \%$ in November 2011 , only $4 \%$ of RH was smaller than $70 \%$, and the monthly average was $92 \pm 9 \%$. Particle microphysical and optical properties measurements were scheduled by the PreViBOSS project ${ }^{1}$ in order to study the impact of aerosols on fog formation and dissipation, and in particular their impact on radiative transfer in the atmosphere. Measurements were performed during three successive fog seasons from October 2010 to March 2013, coinciding with the ParisFog field campaigns. ParisFog is a series of field campaigns hosted by the SIRTA Observatory and dedicated to the description of the physical processes in the fog life cycle under contrasted influence of urban pollution and continental/oceanic air masses. SIRTA is located in a suburban area $25 \mathrm{~km}$ southwest of Paris, the instrumented area covering less than 1 squared kilometre on the Plateau of Ecole Polytechnique (Haeffelin et al., 2005). The first ParisFog field campaign occurred during the autumn-winter season 2006-2007 (Bergot et al., 2008; Haeffelin et al., 2010). All measurements were made in a continuous mode and at high time frequency (Table 1), to avoid missing any events of reduced visibility. Data were uniformly averaged over $15 \mathrm{~min}$. All times are given in Universal Time (UT).

\subsubsection{Aerosol and droplet instrumentation}

Particle size distributions were measured under ambient conditions by two optical particle counters (Table 1). The WhitE Light Aerosol Spectrometer-2000 (WELAS; PALAS Gmbh, Karlsruhe, Germany) and the Fog Monitor-100 (FM100; Droplet Measurement Technologies, Boulder, CO, USA) together provided size distributions of aerosols and droplets with diameters between $0.4 \mu \mathrm{m}$ and $50 \mu \mathrm{m}$ in ambient conditions.

In the WELAS optical chamber, the air sample is illuminated by a white light and the scattered radiation is measured at a scattering angle of $90^{\circ}$ (Heim et al., 2008). It is expected that the WELAS counting efficiency was reduced close to the size detection limits and that the systematic decrease in number concentration towards $0.4 \mu \mathrm{m}$ was an instrumental artefact (Figs. 1 and 2). However, such suspected underestimation of the size distribution would have little impact on extinction coefficient or LWC computation, taking into account the major contribution of particles larger than $\sim 0.8 \mu \mathrm{m}$ diameter to the total particulate surface or volume. The WELAS size output was calibrated in a laboratory with latex particles of a particular size, while the number concentration output was not calibrated. A "reference" instrument was then dedicated to inter-calibrate both the WELAS and the FM100 under field conditions: a co-located DF20+ diffusometer (Degreane Horizon) provided independent measure-

\footnotetext{
${ }^{1}$ http://hygeos.com/fr/previboss.htm
}

ments of both visibility and particle (aerosol and fog droplet) extinction coefficient. A wavelength of $550 \mathrm{~nm}$ is representative of the lamp spectrum. According to the manufacturer, the uncertainty is $\pm 10 \%$ below a visibility of $5 \mathrm{~km}$, and $\pm 15 \%$ between 5 and $20 \mathrm{~km}$ (uncertainties presented in Table 1). Uncertainty of less than $\pm 10 \%$ is not achievable with diffusometer sensors (Crosby, 2003).

In the FM100, the forward-scattered light of a $0.658 \mu \mathrm{m}$ laser beam is measured in the $3-12^{\circ}$ angular range. The default manufacturer's channels were used, which has insignificant impact on measured LWC and total droplet number concentration (Spiegel et al., 2012). The total number concentration can be estimated within $\pm 10 \%$ uncertainty according to Spiegel et al. (2012). Following Spiegel et al. (2012), a Particle Volume Monitor-100 (PVM; Gerber Scientific, Inc., Reston, Virginia, USA) was also running to check the impact of large droplet loss on LWC computations. Measurements by the PVM have a $\pm 15 \%$ uncertainty (Allan et al., 2008).

A TSI Condensation Particle Counter (CPC) instrument mounted behind a $\mathrm{PM}_{2.5}$ inlet also measured aerosol number concentration for dry diameters between $4 \mathrm{~nm}$ and $2.5 \mu \mathrm{m}$. All aerosol and droplet instruments were set up $4 \mathrm{~m}$ above ground level.

\subsubsection{Meteorological data}

Thermohygrometric profiles, cloud base height and precipitation were parameters used to describe the atmospheric conditions prevalent at mist and fog formation and dissipation. Vertical profiles of temperature and $\mathrm{RH}$ were acquired by a $30 \mathrm{~m}$ meteorological mast, with a $\pm 2 \%$ uncertainty in RH. A Vaisala CL31 ceilometer detected the cloud presence above the site and also estimated the cloud base height, at $1 \mathrm{~min}$ resolution. Precipitation was measured by standard gauge devices and sedimentation was observed by a YES TPS310 instrument.

\subsection{Methodology}

Here, we describe the methodology to compute the particle extinction coefficient (Sect. 2.2.1) for several particle populations, which were defined according to the measured size distributions (Sect. 2.2.2). The computed particle extinction coefficients were used to estimate the aerosol contribution to extinction of visible radiation in fog, and also for validation in two steps: computations for aerosols alone in mist, computations for both aerosols and droplets in fog (results in Sect. 4). The distinction between mist and fog is presented in Sect. 3. The LWC computed from FM100 measurements and measured by the PVM was also used for data screening.

\subsubsection{Computation of the particle extinction coefficient}

The particle extinction coefficient, which is usually expressed in $\mathrm{Mm}^{-1}\left(10^{-6} \mathrm{~m}^{-1}\right)$, was derived by two independent methods. The particle extinction coefficient at $550 \mathrm{~nm}$ 
Table 1. Instrumental set-up at SIRTA for the measurement of particle properties in ambient and dry (only CPC) conditions.

\begin{tabular}{|c|c|c|c|c|}
\hline Instrument & Observed parameters & $\begin{array}{l}\text { Particle diame- } \\
\text { ter range }(\mu \mathrm{m})\end{array}$ & $\begin{array}{l}\text { Sampling time } \\
\text { resolution }\end{array}$ & Uncertainty \\
\hline Degreane DF20+ diffusometer & $\begin{array}{l}\text { Visibility } \\
\text { (and extinction coefficient) }\end{array}$ & all & $1 \mathrm{~min}$ & $\pm 10 \%$ (visibility $<5 \mathrm{~km}$ ) \\
\hline Vaisala CL31 ceilometer & $\begin{array}{l}\text { Cloud fraction and cloud base } \\
\text { height }\end{array}$ & all & $30 \mathrm{~s}$ & $\pm 15 \mathrm{~m}$ \\
\hline $\begin{array}{l}\text { PALAS WELAS particle } \\
\text { counter }\end{array}$ & Number size distribution & $0.40-42$ & $5 \mathrm{~min}$ & $\begin{array}{l}\text { Number concentration: } \\
\pm 20 \%\end{array}$ \\
\hline DMT FM100 particle counter & $\begin{array}{l}\text { Number size distribution } \\
\text { (and liquid water content, } \\
\text { droplet effective radius) }\end{array}$ & $2-50$ & $1 \mathrm{~s}$ & $\begin{array}{l}\text { Number concentration: } \\
\pm 10 \%\end{array}$ \\
\hline Gerber PVM & Liquid water content & $3-50$ & $1 \mathrm{~s}$ & $\pm 15 \%$ \\
\hline TSI CPC & $\begin{array}{l}\text { Dry aerosol number concentra- } \\
\text { tion }\end{array}$ & Dry: $0.04-2.5$ & $10 \mathrm{~s}$ & $\pm 10 \%$ \\
\hline
\end{tabular}
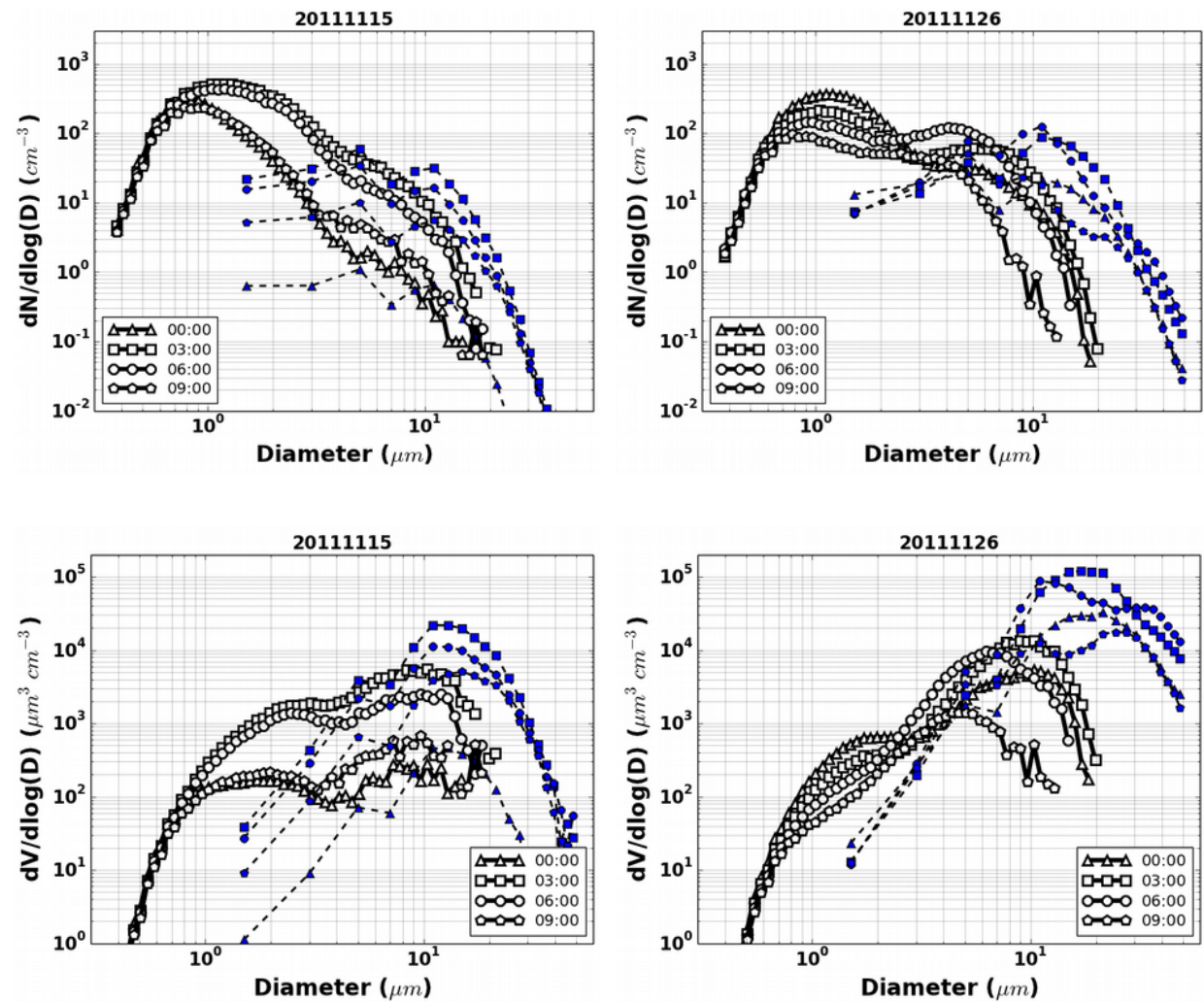

Figure 1. Number (top) and volume (bottom) size distributions measured by the WELAS (open symbols) and by the FM100 (blue filled symbols and dashed lines) during the f5 and f6 fogs of 15 November 2011 (left) and the f16 fog of 26 November 2011 (right), averaged over $3 \mathrm{~h}$.

( pec $_{\mathrm{K}}$ ) was first directly provided by the DF20+, according to the Koschmieder equation (e.g. Hess et al., 1998)

$\operatorname{pec}_{\mathrm{K}}=\frac{-\ln \left(C_{\mathrm{v}}\right)}{\text { visibility }} \times 10^{6}$.
Visibility (in $\mathrm{m}$ ) is a measure of the distance where contrast between an object and its background can be viewed by the unaided eye. With a visual contrast $C_{\mathrm{v}}$ of $5 \%$, fixed by the manufacturer, usual thresholds of 1 and $5 \mathrm{~km}$ in visibility correspond to pec $_{\mathrm{K}}$ of around 3000 and $600 \mathrm{Mm}^{-1}$, respectively. 

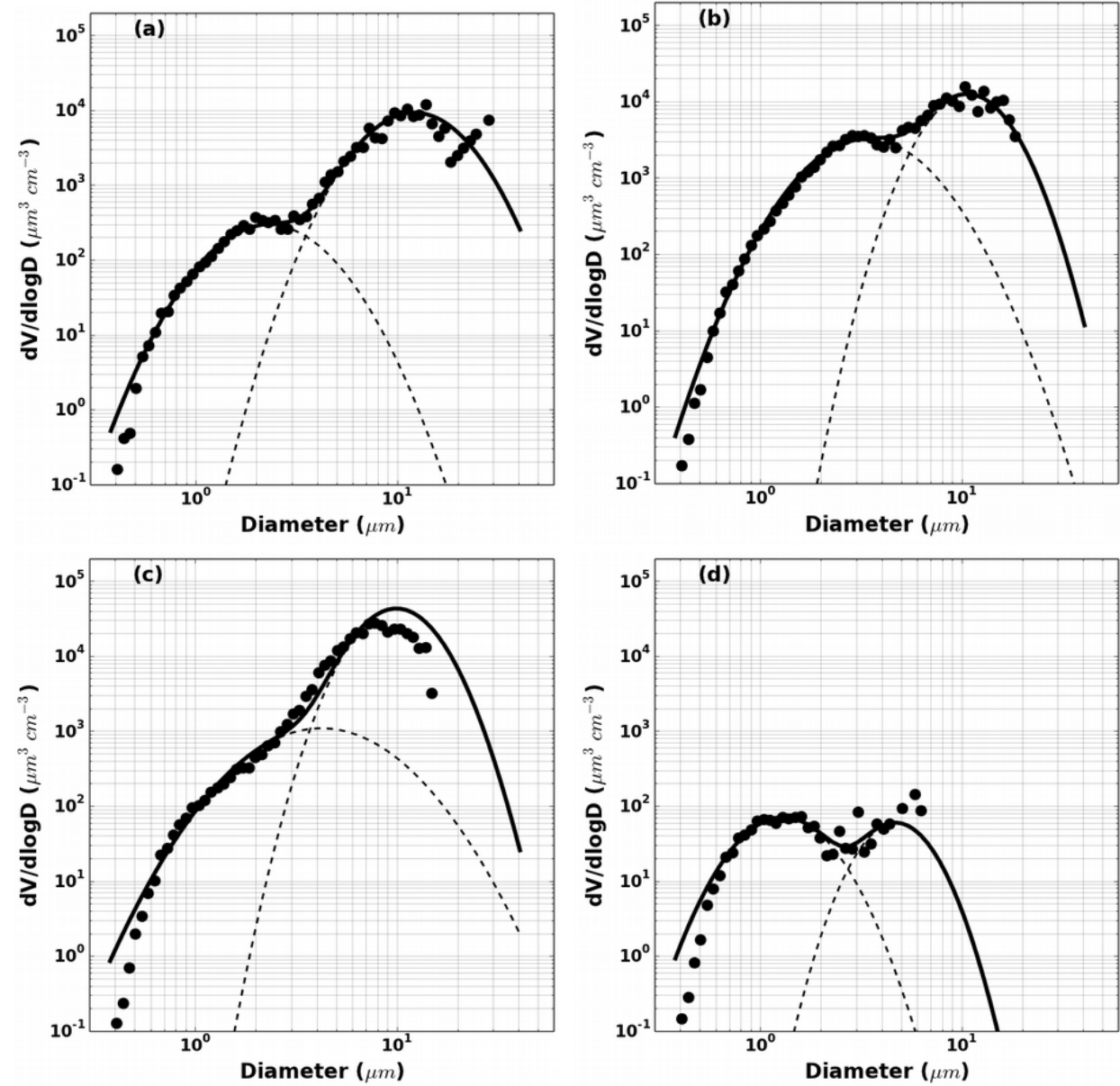

Figure 2. Particle volume size distributions measured by WELAS and averaged at $15 \mathrm{~min}$, during four fogs of November 2011. Measurements are shown by dots, and approximations by log-normal distributions are shown by the lines, dashed lines for the monomodal distributions, and a thick continuous line for the bimodal distribution. (a) 2 November, 02:00 UT, during fog f1; (b) 10 November, 20:00, during fog f2; (c) 26 November, 06:00, during fog 16; (d) 28 November, 07:30, during fog f17.

The particle extinction coefficient ( $\mathrm{pec}_{\mathrm{M}}$ ) was also derived by the Mie theory applicable to spherical aerosol particles (e.g. Bohren and Huffman, 1983):

$\operatorname{pec}_{\mathrm{M}}=\sum_{D_{\min }}^{D_{\max }} \frac{\lambda D^{2}}{4} \Delta N(D) Q_{\mathrm{ext}}(D, \lambda=550 \mathrm{~nm}, m)$

The Mie extinction efficiency factor $Q_{\text {ext }}(D, \lambda, m)$ depends on the radiation wavelength $\lambda$, the particle diameter $D$ (in $\mu \mathrm{m}$ ), and the refractive index $m$, which is assumed to be independent of wavelength, and time. Computations were made at the wavelength of $550 \mathrm{~nm}$, which is representative of the DF20+ lamp spectrum. The AEROsol Robotic NETwork (AERONET) (Holben et al., 1998) provided indicative values of the refractive index of ambient aerosols present in the whole atmospheric column over the SIRTA, on 13, 19, 20 and 22 November 2011. The imaginary part varied between 0.04 and 0.10 , indicating the presence of absorbing particles typical of urban and industrialized pollution (Shet- tle and Fenn, 1979), and the real part varied between 1.40 and 1.55. Consequently, $m=1.45-0.05 \mathrm{i}$ was used for computations for the hydrated interstitial aerosol particles of diameter smaller than $2.5 \mu \mathrm{m}$ and the refractive index of pure water, $m=1.33-0 \mathrm{i}$, was used for the particles larger than $2.5 \mu \mathrm{m}$ in diameter, which are mainly composed of water (Table 2 ); $\Delta N(D)$ is the particle number size distribution (in $\mathrm{cm}^{-3}$ ). $\mathrm{pec}_{\mathrm{M}}$ is directly proportional to the total particle number concentration $N\left(\right.$ in $\mathrm{cm}^{-3}$ ), as

$\operatorname{pec}_{\mathrm{M}}=N \frac{\lambda}{4} \sum_{D_{\min }}^{D_{\max }} D^{2} f(D) Q_{\mathrm{ext}}(D, \lambda=550 \mathrm{~nm}, m)$

with

$N=\sum_{D_{\min }}^{D_{\max }} \Delta N(D)$,

and

$\Delta N(D)=N f(D)$. 
According to computations made by Elias et al. (2009), a $30 \%$ uncertainty was estimated on pec $_{\mathrm{M}}$, taking into account the instrumental errors, the uncertainties from the two systems to provide the particle size distribution $\Delta N(D)$, the assumptions relating to the refractive index, and the assumptions used in the optical property algorithm. Similarly, uncertainties in the scattering coefficient computed by Mie theory were evaluated at $20 \%$, and at $30 \%$ for the absorption coefficient by Wex et al. (2002), at $34 \%$ for the extinction coefficient by Chen et al. (2012), and at $50 \%$ by Yuskiewicz et al. (1998).

For validating the methodology and the data set, comparisons were made between $\operatorname{pec}_{K}$ and $\operatorname{pec}_{M}$ (see results in Sect. 4.1). In mist, the size distribution of aerosols alone (Sect. 2.2.2) measured by WELAS was used in Eq. (2), and in fog, the size distribution of both aerosols and droplets measured by both the WELAS and the FM100 was used. Burnet et al. (2012) showed size distributions acquired by both instruments during the 19 November 2010 fog event at SIRTA. The FM100 values were far smaller than the WELAS values for particles smaller than $5 \mu \mathrm{m}$ in diameter, whereas the WELAS values were smaller than the FM100 values for particles larger than $10 \mu \mathrm{m}$ in diameter. Elias et al. (2009) showed that the WELAS was not efficient enough in measuring the largest fog droplets, the FM100 consequently had the purpose to complement the WELAS with regards to larger particles during this second series of ParisFog campaign. Similarly to Burnet et al. (2012), Fig. 1 shows the particle size distributions for the 15 and 26 November 2011. Size distributions crossed each other around $9 \mu \mathrm{m}$ at 00:00 UT, 15 November and around 7-8 $\mu \mathrm{m}$ later, in both number and volume size distributions (vsd's). On 26 November, size distributions also crossed around 7-9 $\mu \mathrm{m}$, except at the end of the fog (around $5 \mu \mathrm{m}$ ). The junction diameter of $7 \mu \mathrm{m}$ was then chosen for processing all data. The WELAS then provided the size distribution of interstitial hydrated aerosols and droplets smaller than $7 \mu \mathrm{m}$, while the FM100 provided the size distribution of droplets larger than $7 \mu \mathrm{m}$.

The vsd provided by FM100 was also integrated over the particle size to provide the LWC (in $\mathrm{mg} \mathrm{m}^{-3}$ ) (e.g. Wendisch, 1998).

\subsubsection{Definition of hydrated aerosols}

We applied a method to distinguish the aerosols and the fog droplets, which lets the hydrated aerosol size interval vary in fog, in contrast to the fixed aerosol size limit, as, e.g., $5 \mu \mathrm{m}$ by Noone et al. (1992), $3 \mu \mathrm{m}$ by Hoag et al. (1999), and $2.5 \mu \mathrm{m}$ by Elias et al. (2009). Fog is indeed composed of droplets and interstitial non-activated aerosols, and the particle size distribution can be expressed by superimposed lognormal distributions of different particle types (e.g. Whitby, 1978). The WELAS instrument was appropriate to sound the aerosols of the accumulation mode. While the WELAS may not be the best choice to measure aerosols with sizes near the lower bound of the accumulation mode, commonly accepted to be $0.1 \mu \mathrm{m}$, the WELAS is definitely adapted for the upper bound, varying between 1.0 and $2.5 \mu \mathrm{m}$ according to several authors (Noone et al., 1992; Seinfeld and Pandis, 1998). Moreover, diameters in dry conditions are usually given in the literature, whereas we work in ambient conditions where aerosols are usually larger. As long as the mode maximum can be identified by the WELAS, as well as the upper bound, and that most of the mode size range is sounded, we assumed that WELAS could provide the three parameters defining the accumulation mode: number concentration, mode diameter, and width (Heintzenberg, 1994). Examples of mode approximations are shown in Fig. 2. The droplet mode provided by WELAS was also approximated by a log-normal distribution and the transition diameter was defined as the intersection between the two approximated modes.

We chose to approximate vsd's because the transition diameter between hydrated aerosols and fog droplets occurred frequently as a dip, easier to identify than an inflexion in the slope of the number size distribution (nsd). On 15 November, the four nsd decreased with size, from the maxima around $2 \mu \mathrm{m}$ (Fig. 1). The transition between the two modes was marked by a slope inflexion in the nsd around 3 to $5 \mu \mathrm{m}$, and by a dip in the vsd at equal size. A similar observation was made at 00:00 UT on 26 November. More rarely a dip was observed at smaller size in the nsd, as on 26 November at 03:00 and 06:00 UT. On these two dates, the transition diameter was observed at around $2-3 \mu \mathrm{m}$. While the variability in individual fog is shown in Fig. 1, Fig. 2 represents the significant variability between several fogs. Figure 2 also shows that the intersection between the two modes occurred at a diameter larger than the dip or the slope inflexion.

For the computations of pec $_{\mathrm{M}}$ (Eq. 2), we fixed $D_{\min }$ and $D_{\max }$ values as reported in Table 2. In fog, Eq. (2) then becomes

$\operatorname{pec}_{M}=\Delta_{\text {hapec }}{ }_{M}+\Delta_{d} \operatorname{pec}_{M}$

or,

$$
\begin{aligned}
\operatorname{pec}_{\mathrm{M}}= & \Delta_{\mathrm{ha}, D<2.5 \mu \mathrm{mpec}}+\Delta_{\mathrm{ha}, D>2.5 \mu \mathrm{mpec}} \\
& +\Delta_{\mathrm{d}} \operatorname{pec}_{\mathrm{M}},
\end{aligned}
$$

where $\Delta_{\mathrm{d}} \mathrm{pec}_{\mathrm{M}}$ is the droplet contribution, and $\Delta_{\mathrm{hape}} \mathrm{pe}_{\mathrm{M}}$ the aerosol contribution, which can be divided according to the aerosol diameter smaller $\left(\Delta_{\mathrm{ha}, D<2.5 \mu \mathrm{mpec}}\right)$ or larger than $2.5 \mu \mathrm{m}\left(\Delta_{\mathrm{ha}, D>2.5 \mu \mathrm{mpec}}\right)$.

\section{Fog and mist definitions}

In this study, fog is identified with criteria other than the $1 \mathrm{~km}$ convention, as presented in the flow chart of Fig. 3. A detailed explanation and justification of the use of these criteria follows hereafter. 
Table 2. Parameters of the Mie computations (Eq. 2) according to different particle populations. No value is given to the aerosol-droplet transition diameter as it is highly variable from one size distribution to another. Mean value was $4.0 \pm 1.1 \mu \mathrm{m}$.

\begin{tabular}{lrlrl}
\hline Contributing particles to extinction & $D_{\min }(\mu \mathrm{m})$ & $D_{\max }(\mu \mathrm{m})$ & Refractive index & Instruments \\
\hline $\begin{array}{l}\text { Most hydrated aerosols of the accumu- } \\
\text { lation mode }\end{array}$ & 0.4 & 2.5 & $1.45-0.05 \mathrm{i}$ & WELAS \\
\hline $\begin{array}{l}\text { Largest hydrated aerosols of the accu- } \\
\text { mulation mode }\end{array}$ & 2.5 & $\begin{array}{l}\text { Aerosol-droplet } \\
\text { transition diameter }\end{array}$ & $1.33-0 \mathrm{i}$ & WELAS \\
\hline $\begin{array}{l}\text { All particles contributing to extinction } \\
\text { in fog }\end{array}$ & 0.4 & 50 & $1.45-0.05 \mathrm{i} / 1.33-0 \mathrm{i}$ & $\begin{array}{l}\text { WELAS+FM100 } \\
\text { (junction diameter } \\
\text { of 7 } \mu \mathrm{m} \text { ) }\end{array}$ \\
\hline
\end{tabular}

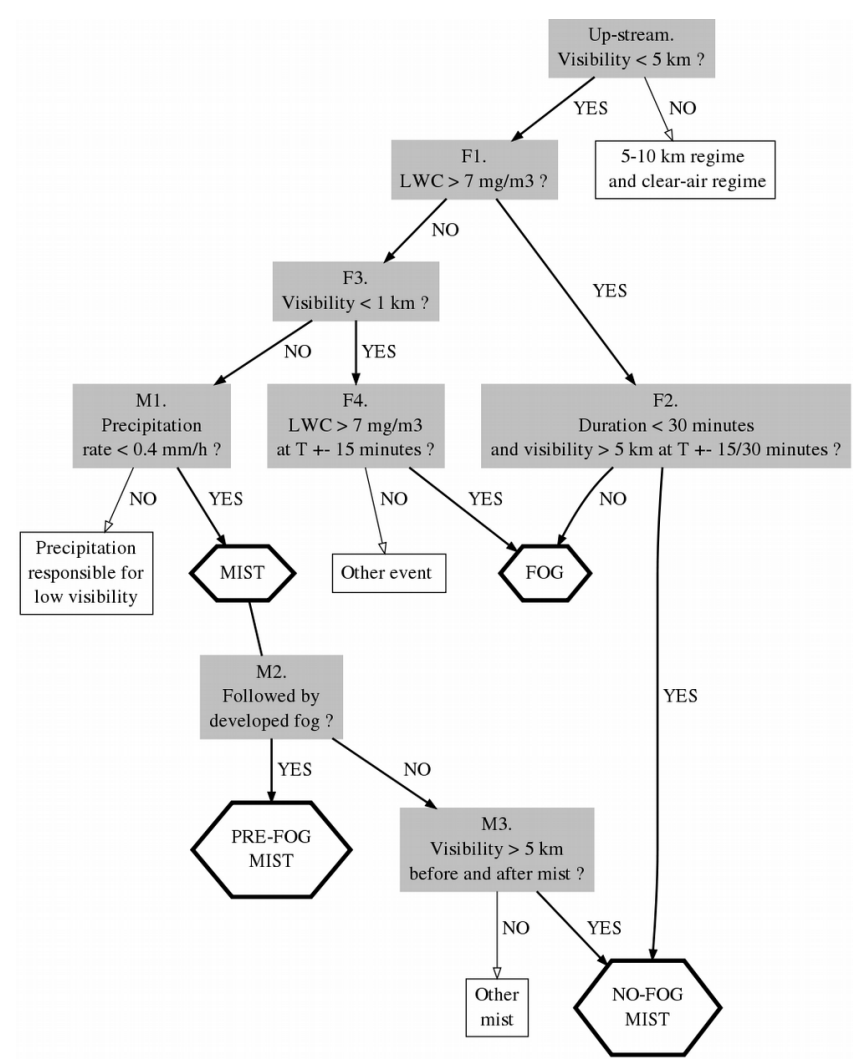

Figure 3. Flow chart of the pre-fog/no-fog mist and fog definitions, according to observations made at SIRTA in November 2011. This flow chart has to be applied every step of $15 \mathrm{~min}$. Criteria are applied at the current time step (T) when not specified. Questions are showed in grey rectangles, and the four appropriate events in hexagons.

\subsection{Fog}

According to the National Oceanic and Atmospheric Administration (1995), fog is a collection of suspended water droplets near the Earth's surface that lead to a reduction of horizontal visibility below $1 \mathrm{~km}$. Aerosols are activated, and droplets form when $\mathrm{RH}$ increases beyond a threshold that is usually between 100 and $101 \%$. The transition over this threshold is difficult to observe because the threshold value depends on various factors (e.g. Hammer et al., 2014b) and uncertainties of RH measurements are usually too large. As stated by Clark et al. (2008), visibility can be a more precise measurement of the impact of RH than the proper measurement of RH. For example, common uncertainty of $1 \%$ in $\mathrm{RH}$ at $\mathrm{RH}>95 \%$ reports as an uncertainty of $20 \%$ in visibility or extinction coefficient (Chen et al., 2012), which is larger than the DF20+ uncertainty.

Consequently, other parameters have to be observed to detect the fog presence. Droplet formation has important consequences for visibility, and fog is conventionally defined according to thresholds on visibility prescribed by transport considerations. However, such thresholds, discussed by Jiusto (1981), also vary, between $400 \mathrm{~m}$ (e.g. Meyer and Lala, 1990) and $5 \mathrm{~km}$ (e.g. Jiusto, 1981). Moreover, both aerosols and droplets affect visibility (e.g. Elias et al., 2009) and visibility may be reduced below $1 \mathrm{~km}$ without droplets but by aerosols (Quan et al., 2011). The event is then called smog (Pearce, 1992) or unactivated fog (Frank et al., 1998). Elias et al. (2009) then proposed a further criterion on temporal gradient of visibility, and Berkowitz et al. (2011) on accumulated precipitation.

Meanwhile, formation of droplets also has important consequences for LWC which is a direct indicator of the condensation process. For example LWC changes by a factor larger than visibility during fog formation (Heintzenberg et al., 1998). In this context, we chose to set a threshold based on LWC values. Fog is defined according to two criteria: on 15 min averages of LWC, and on the time change of LWC over three $15 \mathrm{~min}$ time steps. A flow chart is presented in Fig. 3. First, fog occurred if $\mathrm{LWC}>7 \mathrm{mg} \mathrm{m}^{-3}$ (Question "F1"). Figure 4 shows that LWC ranged from 7 to $20 \mathrm{mg} \mathrm{m}^{-3}$ at visibility of $1 \mathrm{~km}$, not taking into account the few points at 700-900 $\mathrm{m}$ visibility and at $\mathrm{LWC}>7 \mathrm{mg} \mathrm{m}^{-3}$ (discussed below). The lowest bound is then chosen as the threshold for defining fog. This is close to $10 \mathrm{mg} \mathrm{m}^{-3}$ used by Wendisch et al. (1998) as a threshold to consider measurements of LWC. This is also consistent with smallest values of 8 or $9 \mathrm{mg} \mathrm{m}^{-3}$ 


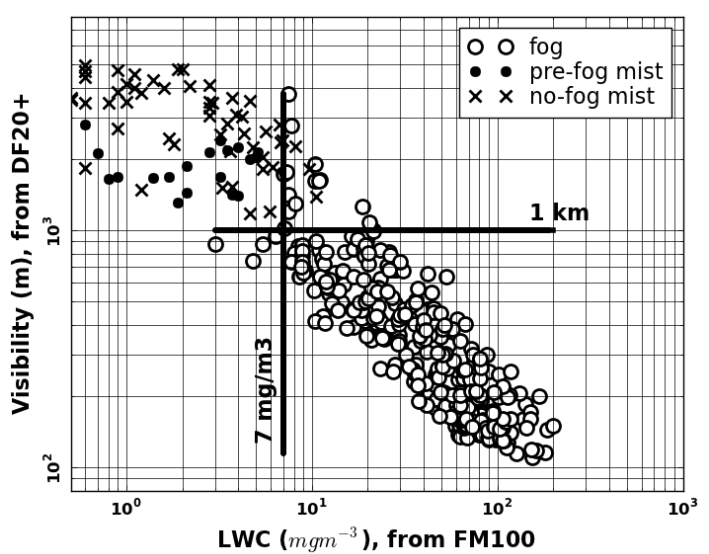

Figure 4. Relationship between visibility, observed by DF20+, and LWC, observed by FM100, during three regimes in November 2011 at SIRTA.

observed in coastal fogs (Jiusto, 1981), and with the threshold of $5 \mathrm{mg} \mathrm{m}^{-3}$ to detect clouds, including thin and heterogeneous clouds (Spiegel et al., 2012). Heintzenberg et al. (1998) set a threshold of $2 \mathrm{mg} \mathrm{m}^{-3}$ for defining fog. This is the minimum possible value for a threshold as aerosols alone can contribute up to few $\mathrm{mg} \mathrm{m}^{-3}$ : haze could contribute up to $1.4 \mathrm{mg} \mathrm{m}^{-3}$ (Eldridge, 1966), or aerosols up to $0.45 \mathrm{mg} \mathrm{m}^{-3}$ at $95 \%$ RH (Pandis and Seinfeld, 1990). Moreover, $7 \mathrm{mg} \mathrm{m}^{-3}$ seems appropriate for long-lasting fogs as according to Eldridge (1966), LWC values below $6 \mathrm{mg} \mathrm{m}^{-3}$ were found only in evolving fog, which is a transition between fog and mist.

In only two cases $\mathrm{LWC}>7 \mathrm{mg} \mathrm{m}^{-3}$ was not declared fog (on 17 and 26 November) because: (1) such events each lasted less than $30 \mathrm{~min}$, and (2) visibility reached values larger than $5 \mathrm{~km}$ before and after these events. Moreover, visibility was larger than $1 \mathrm{~km}$ and averaged LWC did not go beyond $11 \mathrm{mg} \mathrm{m}^{-3}$. Such cases were labelled "no-fog mist". These cases were treated by the Question "F2" of the flow chart (Fig. 3).

Rarely (only 5 times, Fig. 4), LWC was observed smaller than $7 \mathrm{mg} \mathrm{m}^{-3}$, while visibility was less than $1 \mathrm{~km}$ (Question "F3"), and while LWC was larger than $7 \mathrm{mg} \mathrm{m}^{-3}$ during the previous and the next time step (Question "F4"). We can suspect particle losses (Spiegel et al., 2012) in such cases, as the PVM, in contrary to FM100, showed values of LWC larger than $10 \mathrm{mg} \mathrm{m}^{-3}$. Such cases were then defined as fog. Consequently, two trajectories lead to "fog" in the flow chart (Fig. 3), one through the questions "F1" and "F2" and the other one through the questions "F1", "F3" and "F4".

Moreover, according to observations reported by Elias et al. (2012) and Menut et al. (2013), we checked the fog spatial homogeneity and disregarded fog patches. Consistently with Dupont et al. (2015), fog was also defined by a temperature vertical gradient from the surface up to $30 \mathrm{~m}$ height smaller than $0.04{ }^{\circ} \mathrm{C} \mathrm{m}^{-1}$ (Elias et al., 2012). This upstream criterion is not mentioned in the flow chart.

Fog visibility was observed between 1 and $3 \mathrm{~km}$ (Fig. 4), on 14 occasions, when fog usually formed or dissipated. Consistently, Meyer et al. (1980) observed that droplets were formed at $1-2 \mathrm{~km}$ visibility range, and Jiusto (1981) defined light fog by visibility between 1 and $5 \mathrm{~km}$. Such visibility was caused by few rather large droplets that contributed more to LWC and less to the extinction coefficient: the droplet effective diameter was larger than the monthly average of $15 \pm 3 \mu \mathrm{m}$, similar to Wendisch et al. (1998), and droplet number concentration was smaller $\left(8-45 \mathrm{~cm}^{-3}\right)$ than the monthly average of $100 \pm 50 \mathrm{~cm}^{-3}$. That high values of fog visibility demonstrate that the diffusometer alone is not able to distinguish the main cause of the visibility reduction, between aerosols or droplets.

\subsection{Mist}

The visibility change during the mist-fog transition was due to the droplet formation, while most visibility changes in mist occurred due to aerosol growth. While fog is defined by $\mathrm{LWC}>7 \mathrm{mg} \mathrm{m}^{-3}$, mist is defined by $\mathrm{LWC}<7 \mathrm{mg} \mathrm{m}^{-3}$. Since mist was a low visibility event, we also defined mist by visibility $<5 \mathrm{~km}$ (question "up stream" in Fig. 3). Not only aerosols or fog droplets are responsible for the visibility reduction, but also rain drops, and a further criterion was applied to discard rain. Mist is defined by a precipitation rate smaller than $0.4 \mathrm{~mm} \mathrm{~h}^{-1}$ (question "M1" in Fig. 3), which was the detection limit of the instrument.

Consistently with Heintzenberg et al. (1998), the impact of the fog formation was stronger on LWC than on visibility: average LWC in mist was found to be smaller than in fog by a factor of 50 , while the average visibility in mist was a factor of only 5 to 11 higher than that in fog (Table 3). Quan et al. (2011) showed that haze and mist are usually distinguished according to RH: haze is relatively dry and mist is more humid. Consistently, mist RH at SIRTA was included between $93 \%$ and $100 \%$, with a monthly average of $99 \%$. At SIRTA, thick haze in dry conditions reducing visibility below $5 \mathrm{~km}$ did not occur in November 2011. With values of $\mathrm{RH}>93 \%$, we expect that aerosols responsible for low visibility were hydrated. In this paper "hydrated aerosols" are defined as the aerosols of the accumulation mode which are responsible for visibility reduction in mist, and measured by the WELAS.

\subsection{The mist-fog-mist cycle and the no-fog mist}

Some mist events preceded fog events, others followed the fog events, and some could be intermediate between two fog events. They were named pre-fog (Question "M2" in Fig. 3), post-fog, and in-fog. The mist-fog-mist cycle was defined as a continuous low visibility event (visibility $<5 \mathrm{~km}$ ), with water droplets observed for at least $45 \mathrm{~min}$. The chronolog- 


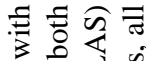

3.040

एें एक त

률

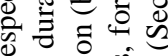

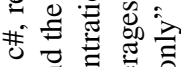

$x$ 잉

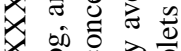

은 을

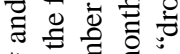

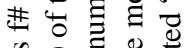

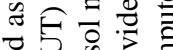

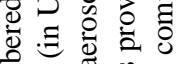

音总苛

㱐

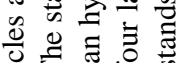

U. ⿷匚

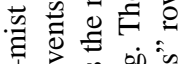

To वे on

I

番 0

焉它

कo

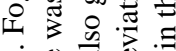

$<$ ब

党

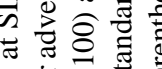

च 후일

ते

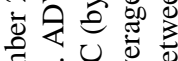

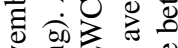

。ำ

乙

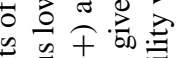

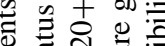

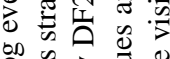

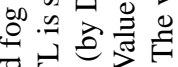

ôn

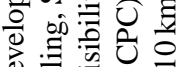

응 $>1$

○ 0 on

on. 范

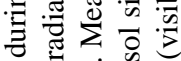

马.

$2 D_{0}^{\circ} \overline{0}$

造

就寻

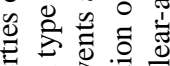

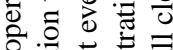

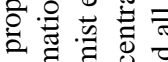

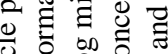

0 잉

过它

的苛吉吉

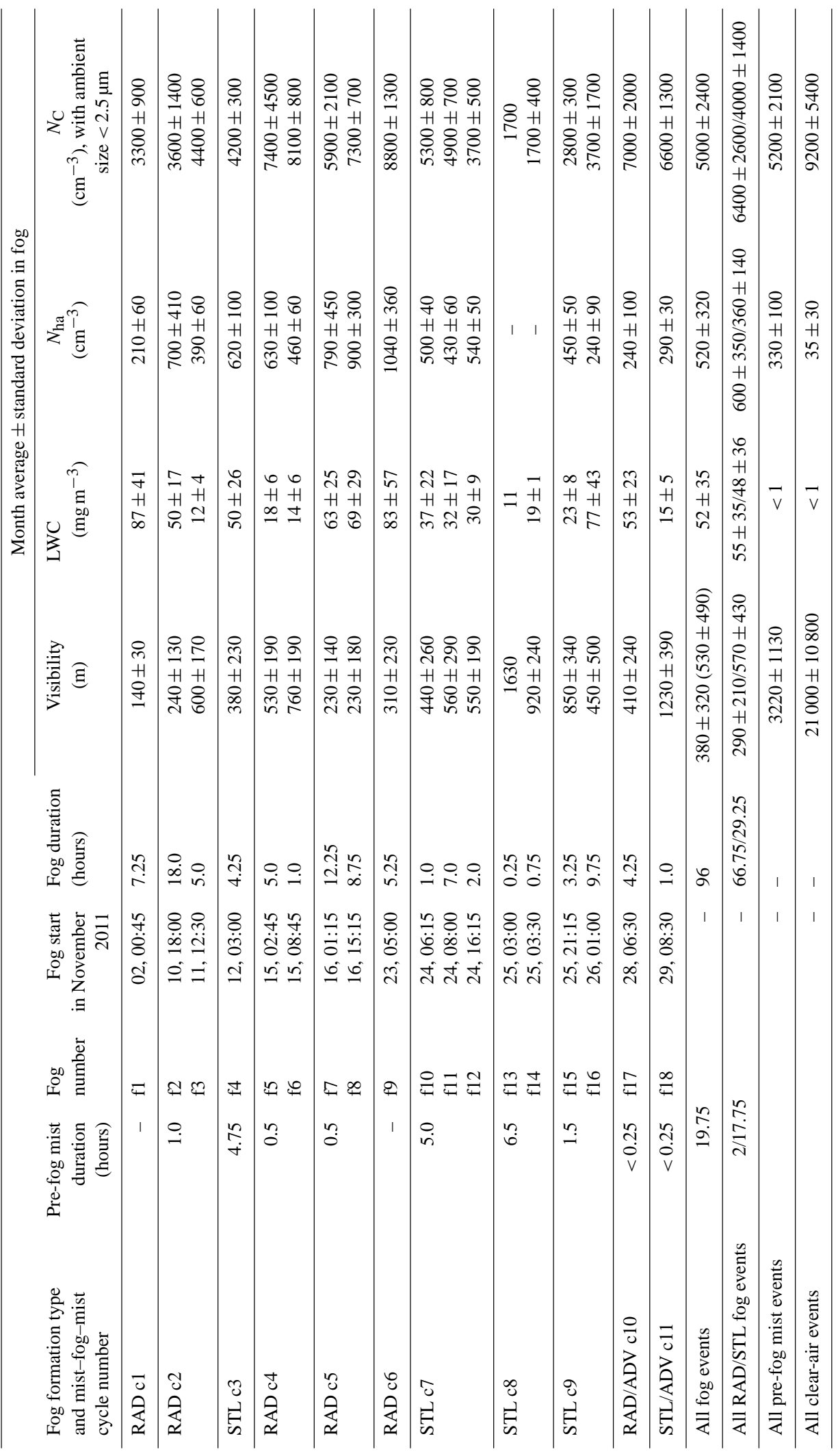

을 
ical sequence is composed basically as mist-fog-mist, but also as mist-fog-mist-fog-mist, etc. Fog was always preceded by mist. Table 3 indicates that pre-fog mist was not observed in two cases (c10 and c11). Indeed, pre-fog mist was not observed in the $15 \mathrm{~min}$ step data set because visibility decreased from $10 \mathrm{~km}$ to less than $1 \mathrm{~km}$ in $15 \mathrm{~min}$, but would be definitely observed in the $1 \mathrm{~min}$ time resolution. In two other cases ( $\mathrm{c} 1$ and $\mathrm{c} 6$ ), mist was not observed before the fog formation, because they started as shallow fog patches, and the pre-fog mist then occurred before the formation of the shallow fog patches, which are disregarded here. Mean visibility in the pre-fog mist was $3100 \pm 1100 \mathrm{~m}$.

No-fog mist was also a low visibility event (visibility $<5 \mathrm{~km}$ ), but which did not occur before or after a fog event (Question "M3" in Fig. 3). Clear-air was defined by visibility larger than $10 \mathrm{~km}$. As a result of the described protocol applied to November 2011 SIRTA data, 18 fogs aggregated into 11 mist-fog-mist cycles were observed, for a cumulated mist-fog-mist cycle duration of $240 \mathrm{~h}$, and a cumulated fog duration of $95 \mathrm{~h}$ (and during other $50 \mathrm{~h}$ of shallow fog). Visibility was also observed to be smaller than $5 \mathrm{~km}$ during a cumulated duration of around $45 \mathrm{~h}$ of no-fog mist. Pre-fog mist and fog properties are presented in Table 3.

\subsection{Fog formation types}

The cloud fraction measured by the CL31 ceilometer was used to distinguish the main fog formation process (e.g. Tardif and Rasmussen, 2007) observed at SIRTA. The cloud fraction is $N_{\text {clouds }} / 15$, with $N_{\text {clouds }}$ the number of minutes (1 min CL31 measurement period) when cloud was observed, in a 15 min time step. Cloud fraction was averaged during the $5-10 \mathrm{~km}$ visibility event preceding the mist-fog-mist cycle, and the associated standard deviation was computed. The distribution of the cloud fraction values showed two distinct modes: when the cloud fraction was larger than $70 \%$, with a standard deviation smaller than $30 \%$, the fog formed due to stratus lowering (STL); when the cloud fraction was smaller than $30 \%$, with a standard deviation smaller than $30 \%$, the fog formed by radiative cooling (RAD). All cases observed at SIRTA were classified according to these thresholds. Six fog life cycles started after radiative cooling and five due to STL. Our fog identification generally agrees with the method of Tardif and Rasmussen (2007) applied by Menut et al. (2013) for only the radiative fogs of November 2011 at SIRTA. Our method is however more detailed concerning the exact start and end times and the fog interruptions by mist (Table 3 ). For example, the mist-fog-mist cycles $\mathrm{c} 1, \mathrm{c} 4, \mathrm{c} 5$ and $\mathrm{c} 10$ correspond to the Fog Observation Periods FOP1, FOP2, FOP3 and FOP9 of Menut et al. (2013). The c6 event which started as a shallow fog corresponds to the FOP8 identified as entirely shallow by Menut et al. (2013). The c2 event is not listed by Menut et al. (2013) and consistently with our method the 26 November fog is not listed either, but in con- trast the short fog event of $17-18$ November is considered (FOP4).

Rapid changes of visibility observed before fog formation in the c10 and c11 cycles could be due to fog advection to SIRTA. Indeed the wind speed increased to more than $2 \mathrm{~m} \mathrm{~s}^{-1}$ at the $\mathrm{c} 10 \mathrm{fog}$ onset, and it was even larger during the c11 mist-fog-mist cycle. Such conditions favour advective fog formation as described by Tardif and Rasmussen (2007). Low cloud ceiling (cloud base height smaller than $800 \mathrm{~m}$ ) before the $\mathrm{c} 11$ fog formation, suggests that the stratus was pushed away while the fog was advected to SIRTA, which seemed similar to the "CBL fog 1" category defined by Van Schalkwyk and Dyson (2013). We added the term ADV (advective) to name these two events.

Mist preceding STL fog usually lasted longer than mist preceding RAD fog (Table 3). Indeed pre-fog mists lasted less than 1 hour in RAD mist-fog-mist cycles, while three pre-fog mists lasted more than $4 \mathrm{~h}$ in STL mist-fog-mist cycles. Consequently, we observed only 2 cumulated hours of pre-fog mist for RAD fogs, and 17.75 of pre-fog mist before STL fogs (Table 3). As also observed by Tardif and Rasmussen (2007), RAD fogs were on average more opaque than STL fogs, with visibility of $290 \pm 210$ and $570 \pm 430 \mathrm{~m}$, respectively. Larger droplets were observed in STL than in RAD fogs, with the droplet effective radius of $8.0 \pm 1.2$ and $6.8 \pm 1.4 \mu \mathrm{m}$, respectively. Consistently, fog visibility observed larger than $1200 \mathrm{~m}$ occurred only in STL (especially during f13 and f18 fogs; Table 3) and never in RAD fogs. Moreover, larger LWC occurred in RAD than in STL fogs (Table 3). Contrary to Tardif and Rasmussen (2007), the longest fog events were found to result from radiative cooling, such as the $\mathrm{f} 2$ and $\mathrm{f} 7 \mathrm{fogs}$ which lasted more than $12 \mathrm{~h}$ each (Table 3).

The average cloud base height was always smaller than $120 \mathrm{~m}$ above pre-fog mist, according to the ceilometer. A low cloud ceiling is indeed expected in the STL fog formation process, but a low ceiling was also observed in the RAD fog formation process. RAD fogs formed as an elevated fog layer in November 2011 at SIRTA when visibility at surface level was already smaller than $5 \mathrm{~km}$, after nocturnal radiative cooling. The typical case of the c4 mist-fog-mist cycle (15 November 2011) was presented in detail by Stolaki et al. (2014): the fog formed at around $150 \mathrm{~m}$ above ground level (a.g.l.), and in $30 \mathrm{~min}$ the fog base reached the surface. During other months of the ParisFog field campaign, some RAD fogs were also observed to appear at surface level and not as an elevated fog layer (Dupont et al., 2015). Low cloud cover was also observed above in-fog mist, meaning that the interruption of a fog in a same mist-fog-mist cycle was due to stratus lifting and lowering. 

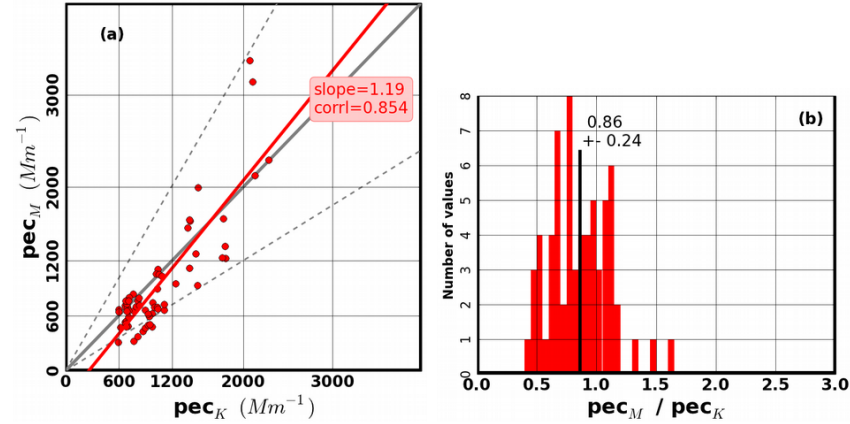

Figure 5. A comparison between the particle extinction coefficient measured by $\mathrm{DF} 20+\left(\mathrm{pec}_{\mathrm{K}}\right)$ and that computed by Mie theory $\left(\mathrm{pec}_{\mathrm{M}}\right)$ applied on the size distributions measured by WELAS, in the pre-fog mist regime of November 2011. Refractive index is 1.45-0.05i. (a) $\operatorname{pec}_{\mathrm{M}}$ function of $\operatorname{pec}_{\mathrm{K}}$, the linear correlation is plotted in red, with corresponding slope value and correlation coefficient ("corrl"). The $1: 1$ and the $\pm 40 \%$ lines are plotted in grey. (b) frequency distribution of the ratio $\mathrm{pec}_{\mathrm{K}} / \mathrm{pec}_{\mathrm{M}}$. The average is indicated with a black, thick line, and average standard deviation is also written in black.

\section{Results}

\subsection{Validation of the instrument set-up and methodology}

A closure study was performed, by estimating the particle extinction coefficient with two independent methods and making comparisons. The efficiency of the WELAS to probe aerosols was examined by making comparisons in mist, and the efficiency of combined WELAS and FM100 to probe both aerosols and droplets contributing to extinction, was examined by making comparisons in fog. Values of the ratio $\mathrm{pec}_{\mathrm{M}} / \mathrm{pec}_{\mathrm{K}}$ for different events are given in Table 4 .

\subsubsection{Aerosols responsible for low visibility in mist}

The particle extinction coefficient measured by the DF20+ was reproduced by the WELAS measurements and Mie theory (within combined uncertainties of $40 \%$ ) when hydrated aerosols of the accumulation mode were responsible for the visibility reduction. This was the case in mist preceding fogs (Fig. 5) with an average ratio $\mathrm{pec}_{\mathrm{M}} / \mathrm{pec}_{\mathrm{K}}$ of $86 \pm 22 \%$, when pec $_{\mathrm{K}}$ varied between 600 and $2200 \mathrm{Mm}^{-1}$. A fraction of the underestimation observed below $1000 \mathrm{Mm}^{-1}$ could be due to the underestimation of the hydrated aerosol number concentration at diameters smaller than $\sim 0.8 \mu \mathrm{m}$.

\subsubsection{Combined WELAS and FM100 in fog}

Agreement between measurements and computations was also satisfying in fog (Fig. 6), when WELAS and FM100 measurements were combined, with an average ratio of $109 \pm 35 \%$. During the f1 and f9 fogs, FM100 measurements showed a high number of droplets larger than $20 \mu \mathrm{m}$
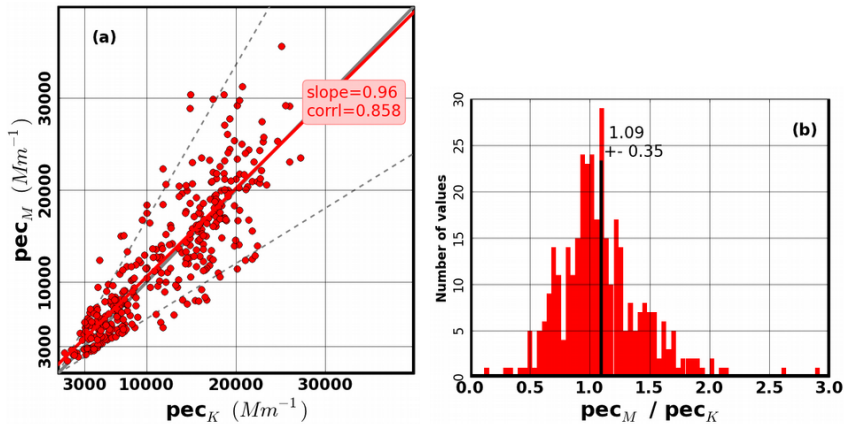

Figure 6. As in Fig. 5 but for the fog regime. The size distribution is generated by combining WELAS and FM100, and two values of the refractive index are used (see text).

which made LWC increase above $200 \mathrm{mg} \mathrm{m}^{-3}$. These high values were judged incorrect because pec $_{M}$ was much larger than pec $_{\mathrm{K}}$, and LWC was also much larger than the LWC provided by PVM. These data were consequently screened out from the data set and PVM and FM100 eventually agreed in LWC with a slope of 0.80 (not shown), similarly to results by Burkard et al. (2002). Moreover, the relation between LWC and visibility shown in Fig. 4 was consistent with observations presented by Heintzenberg et al. (1998). Therefore, the WELAS and FM100 combined together were considered appropriate to measure both aerosols and droplets responsible for extinction in fog. Moreover, according to the agreement in the particle extinction coefficient, in both pre-fog mist and fog events, we consider that WELAS provided the aerosol number concentration in ambient conditions in fog with sufficient precision.

The measurements also show that the WELAS could not properly count the particles responsible for visibility reduction in other conditions: rain and drizzle (Sect. 4.1.3), or large thermal vertical gradient. The FM100 was indeed observed to miss droplets in shallow fog patches (Elias et al., 2012), which were consequently not considered here. Similarly, the WELAS alone did not reproduce the extinction coefficient in mist preceding shallow fog patches. Moreover, we have noted that even in cloud-free no-fog mist, $\mathrm{pec}_{\mathrm{M}} / \mathrm{pec}_{\mathrm{K}}$ reduced to $53 \pm 23 \%$ if the temperature vertical gradient was larger than $0.04^{\circ} \mathrm{C} \mathrm{m}^{-1}$, and reached $95 \pm 21 \%$ if it was smaller (Table 4). That shows that the criterion on the thermal vertical gradient seems discriminative for defining the optimal measurement conditions of the WELAS.

\subsubsection{Drops missed by both WELAS and FM100}

The mist and fog criteria (Fig. 3) disregarded the low visibility events caused by rain (Question "M1" in Fig. 3). We discuss these situations in this section to provide hints on specific cases when the particle counters do not provide satisfaction in regards to aerosols and fog droplets. Visibility was reduced below $5 \mathrm{~km}$ by drops during eleven rain events, 
Table 4. Values of the average ratio $\operatorname{pec}_{\mathrm{M}} / \mathrm{pec}_{\mathrm{K}}$ for different events; cbh is cloud base height, and $\Delta T$ is the vertical thermal gradient.

\begin{tabular}{|c|c|c|c|}
\hline Event & \multicolumn{2}{|c|}{ Further conditions } & $\operatorname{pec}_{M} / \operatorname{pec}_{K}(\%)$ \\
\hline \multirow{5}{*}{ No-fog mist } & & - & $66 \pm 32$ \\
\hline & \multicolumn{2}{|c|}{$\mathrm{cbh}<100 \mathrm{~m}$} & $43 \pm 20$ \\
\hline & \multirow{3}{*}{ Cloud-free sky } & - & $78 \pm 30$ \\
\hline & & $\Delta T>0.04^{\circ} \mathrm{m}^{-1}$ & $53 \pm 23$ \\
\hline & & $\Delta T<0.04^{\circ} \mathrm{m}^{-1}$ & $95 \pm 21$ \\
\hline Pre-fog mist & & - & $86 \pm 22$ \\
\hline Fog & & - & $107 \pm 35$ \\
\hline $\begin{array}{l}\text { Rain events (precipitation } \\
\text { rate }>0.4 \mathrm{~mm} \mathrm{~h}^{-1} \text { ) }\end{array}$ & & - & $25 \pm 12$ \\
\hline
\end{tabular}

with a precipitation rate larger than $0.4 \mathrm{~mm} \mathrm{~h}^{-1}$. As the drop size exceeded both the WELAS and FM100 sensitivity domains, these instruments could not provide the size distribution of all particles responsible for the visibility decrease, and pec $_{\mathrm{M}} /$ pec $_{\mathrm{K}}$ was only $25 \pm 12 \%$ during these events (Table 4). Similarly, we suspect that large particles undetected by the particle counters were sometimes responsible for the visibility reduction below $5 \mathrm{~km}$, still with a precipitation rate smaller than $0.4 \mathrm{~mm} \mathrm{~h}^{-1}$. These large particles could be caused by drizzle, expected when the cloud ceiling was very low. Indeed, $\mathrm{pec}_{\mathrm{M}} / \mathrm{pec}_{\mathrm{K}}$ was only $43 \pm 20 \%$ (Table 4) when the cloud base height was smaller than $100 \mathrm{~m}$ (according to the CL31 ceilometer) in no-fog mist. However, the WELAS observations were validated in no-fog mist below cloud-free sky, as $\operatorname{pec}_{M} / \operatorname{pec}_{\mathrm{K}}$ was $78 \pm 30 \%$, with a main mode included between 50 and $120 \%$, as for pre-fog mist. Moreover, the TPS310 instrument confirmed the suspicion of drizzle in three of these low-cloud ceiling no-fog mist events, as it showed a signal of sedimentation at a rate of less than $0.4 \mathrm{~mm} \mathrm{~h}^{-1}$, not detectable by a standard rain sensor.

In post-fog mist conditions, the WELAS instrument was unable to measure all aerosols contributing to extinction, as already observed by Elias et al. (2009) for one case study of February 2007. In November 2011, visibility was similar in pre-fog and post-fog mists, but the hydrated aerosol number concentration was $40 \%$ smaller in post-fog mist. Drizzle may then often occur after the fog dissipations, with drizzle drops beyond the size domain sensitivity of the particle counters.

These observations also indicate that at SIRTA fogs formed in November 2011 after mist composed by hydrated aerosols, and never after rain neither drizzle. Consistently, Haeffelin et al. (2013) also observed that liquid water deposition $(0.2 \mathrm{~mm}$ accumulated precipitation in $3 \mathrm{~h})$ prevented vertical development of a fog layer at SIRTA on 20 February 2007.
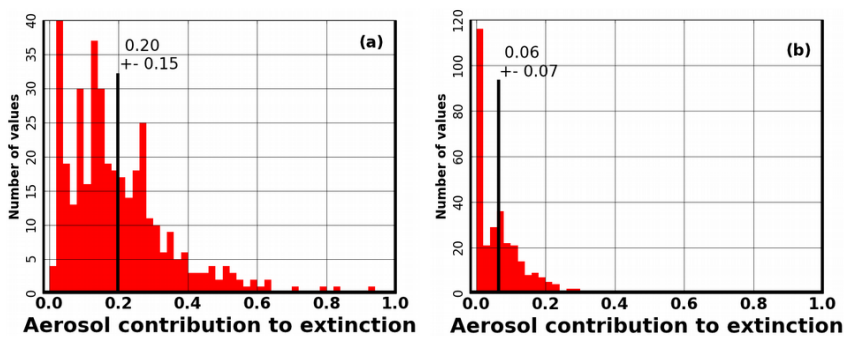

Figure 7. The contribution of hydrated aerosols to extinction of visible radiation in fogs observed during November 2011. (a) For aerosols smaller than $2.5 \mu \mathrm{m}$ in diameter $\left(\Delta_{\text {hapec }}\right)$, (b) for aerosols larger than $2.5 \mu \mathrm{m}\left(\Delta_{D>2.5} \mu \mathrm{mpec} M\right)$

\subsection{Contribution to fog extinction by hydrated aerosols}

Aerosols contributed significantly to the extinction of visible radiation in fog. It is known that visibility in fog is mainly governed not only by LWC (Fig. 4) but also by the particle size. Indeed, for constant LWC, visibility decreases with decreasing particle size. Following this principle, aerosols are too small to contribute significantly to LWC but can not be neglected in terms of extinction. Consequently, the hydrated aerosols smaller than $2.5 \mu \mathrm{m}$ contributed to the extinction of visible radiation observed in fog up to $\Delta_{\text {ha, } D<2.5 \mu m p e c} / \operatorname{pec}_{\mathrm{K}}=20 \pm 15 \%$ (Fig. 7a), with $\pm 8 \%$ uncertainty, and the hydrated aerosols larger than $2.5 \mu \mathrm{m}$ contributed as $\Delta_{\mathrm{ha}, D>2.5} \mu \mathrm{mec}_{\mathrm{M}} / \mathrm{pec}_{\mathrm{K}}=6 \pm 7 \%$ (Fig. 7b). $\Delta_{\text {ha }, D<2.5 \mu m}$ pec $_{\mathrm{M}} /$ pec $_{\mathrm{K}}$ partly depended on fog visibility, as it was smaller than $5 \%$ in long-lasting fogs where visibility was often smaller than $200 \mathrm{~m}$, as during f1, f2, and f16 fogs, and it was smaller than $20 \%$ when visibility was smaller than $600 \mathrm{~m}$. In contrast, it was between 40 and $70 \%$ when fog visibility was between 300 and $1000 \mathrm{~m}$. A dependence on visibility was not found for $D>2.5 \mu \mathrm{m}$. $\Delta_{\text {ha }, D<2.5 \mu \mathrm{mpec}}$ was $1800 \pm 1100 \mathrm{Mm}^{-1}, 5$ to 10 times larger than values given by Hess et al. (1998), 
Table 5. Averaged values of the aerosol extinction cross section $\left(10^{-8} \mathrm{~cm}^{2}\right)$ computed by two methods, for different size intervals, and for both pre-fog mist and fog. The method "DF20+ and WELAS" means the slope is computed between $\operatorname{pec}_{\mathrm{K}}$ and $N_{\text {ha. }}$. The method "WELAS and Mie theory" means that $\operatorname{pec}_{M}$ is divided by $N_{\text {ha. }}$.

\begin{tabular}{llll}
\hline Method & DF20+ and WELAS & \multicolumn{2}{l}{ WELAS and Mie theory } \\
\cline { 3 - 4 } Diameter range $(\mu \mathrm{m})$ & Full range & $D<2.5$ & Full range \\
\hline Pre-fog mist & 3.0 & $2.4 \pm 0.4$ & $2.5 \pm 0.5$ \\
Fog & - & $3.5 \pm 0.5$ & $4.3 \pm 1.1$ \\
\hline
\end{tabular}

due to the influence of aerosol growth from 80 to almost $100 \%$ RH. It was only $50 \%$ larger than the value given by Yuskiewicz et al. (1998) for a highly polluted environment. The mass extinction cross section (Hess et al., 1998) decreased from around $3 \mathrm{~m}^{2} \mathrm{~g}^{-1}$ in clear conditions to around $2 \mathrm{~m}^{2} \mathrm{~g}^{-1}$ in fog. As shown by Hess et al. (1998), the mass extinction cross section undergoes a decrease with increasing size, which was partly compensated by the fog water density, smaller than the aerosol density.

Visibility parameterizations incorporated in numerical modelling of fog usually consider only droplets (e.g. Gultepe et al., 2006; Stolaki et al., 2014). We present the consequences of not considering aerosols. According to Eq. (5a), if $\operatorname{pec}_{\mathrm{K}}=\operatorname{pec}_{\mathrm{M}}$, the droplet extinction coefficient is

$\Delta_{\mathrm{d}} \operatorname{pec}_{\mathrm{M}}=\operatorname{pec}_{\mathrm{K}}-\Delta_{\mathrm{hapec}}$,

or

$\Delta_{\mathrm{d}} \mathrm{pec}_{\mathrm{M}}=\operatorname{pec}_{\mathrm{K}}-<\operatorname{aecs}>N_{\mathrm{ha}}$,

where $<$ aecs $>$ is the average aerosol extinction cross section, which represents the efficiency of one particle to extinguish visible radiation, and $N_{\mathrm{ha}}$ is the hydrated aerosol number concentration. $<$ aecs $>$ varied between 2.4 and $4.3 \times$ $10^{-8} \mathrm{~cm}^{2}$, depending on the method, the aerosol diameter range and the mist/fog event (Table 5). We observed a correlation between pec $_{\mathrm{K}}$ and $N_{\mathrm{ha}}$ (Fig. 8) in mist, providing $<$ aecs mist $>=3.0 \times 10^{-8} \mathrm{~cm}^{2}$. Dividing the mean particle extinction coefficient $\left(1050 \mathrm{Mm}^{-1}\right)$, according to DF20+, by the mean aerosol number concentration $\left(330 \mathrm{~cm}^{-3}\right)$ provided a similar value in mist. It is interesting to note that such a method does not depend on the size attribution by WELAS. Because of the aerosol size increase in fog, $<\operatorname{aecs}_{f_{0}}>$ was slightly larger than $<$ aecs mist $>$. Dividing $\Delta_{\text {hapec }}$ by $N_{\text {ha }}$ in fog resulted in $<$ aecs $_{\text {fog }}>=3.5 \times 10^{-8} \mathrm{~cm}^{2}$ for $D<2.5 \mu \mathrm{m}$ and in $<$ aecs $_{\text {fog }}>=4.3 \times 10^{-8} \mathrm{~cm}^{2}$ for aerosols both below and beyond $2.5 \mu \mathrm{m}$ (Table 5 ).

The impact of not considering aerosols in fog visibility is significant, as visibility of $380 \pm 320 \mathrm{~m}$ was observed, while the value of $530 \pm 490 \mathrm{~m}$ was computed without aerosols (for a constant value of LWC), setting $<$ aecs $>=3.5 \times 10^{-8} \mathrm{~cm}^{2}$ in Eq. (6b). When only droplets were considered, the number of visibility values around $400 \mathrm{~m}$ was critically reduced, and more values were found between 1 and $2 \mathrm{~km}$. As a consequence, with the $1 \mathrm{~km}$ convention to detect fog, a proportion of $17 \%$ of the fog duration would be missed by considering only extinction due to droplets, while only $4 \%$ of the fog events would be missed by considering both aerosols and droplets. For example, fog would last only $2.5 \mathrm{~h}$ during the $\mathrm{c} 4$ mist-fog-mist cycle, instead of the 6 observed cumulated hours, and it would start $30 \mathrm{~min}$ later than what was observed according to the LWC threshold (Table 3). Similarly, Ahmed et al. (2014) show that the minimum droplet concentration necessary to reach $1 \mathrm{~km}$ visibility is reduced if aerosols are considered, with consecutive impact on fog detection by satellite.

As soon as supersaturation occurred, the visibility drop in some fogs did not occur only due to droplet formation but also due to the increase of $N_{\text {ha }}$. Indeed, at RAD f8 and f9 fog onsets, the contribution by hydrated aerosols alone could be larger than $3000 \mathrm{Mm}^{-1}$, resulting in a contribution to fog extinction between 30 and $50 \%$. Table 3 shows that these both fogs formed in polluted conditions, with month averages of $N_{\mathrm{C}}>7000 \mathrm{~cm}^{-3}$ and $N_{\mathrm{ha}}>900 \mathrm{~cm}^{-3}$. Associated significant aerosol extinction and large LWC result in mean fog visibility $<310 \mathrm{~m}$. However, at SIRTA, such high aerosol extinction coefficient was never observed outside a fog event. The influences of both $N_{\text {ha }}$ and the aerosol size on the aerosol contribution to extinction are described in next Section.

\subsection{Hydrated aerosol microphysical properties}

\subsubsection{Hydrated aerosol number concentration}

In pre-fog mist, the aerosol growth due to hydration caused both an increase of $N_{\mathrm{ha}}$ and the visibility reduction. Increasing RH induced an increasing aerosol growth factor (Chen et al., 2012), and with $\mathrm{RH}>93 \%$, pec $\mathrm{K}_{\mathrm{K}}$ increased from 600 to $2200 \mathrm{Mm}^{-1}$ in pre-fog mist (Fig. 8a), and $N_{\text {ha }}$ increased from 160 to $600 \mathrm{~cm}^{-3}$, similarly to observations presented by Kunkel (1984).

Moreover, on average, $60 \%$ more hydrated aerosols were observed in fog than in mist, with $330 \pm 100 \mathrm{~cm}^{-3}$ in mist and $520 \pm 320 \mathrm{~cm}^{-3}$ in fog (Table 3). This is similar to the mean number concentration of the dry aerosols of the accumulation mode observed by Yuskiewicz et al. (1998) in fog. The standard deviation in fog was larger than in mist by a factor of 3 , as the fog average of $N_{\text {ha }}$ varied by a factor of 5 (Table 3 ), and instantaneous value could vary by a factor of 3 during the same fog event. For example, during the f9 fog the number concentration decreased by more than $1000 \mathrm{~cm}^{-3}$ in $5 \mathrm{~h}$, while during the $\mathrm{f} 2 \mathrm{fog}$ it increased by an equivalent magnitude. During both $\mathrm{f} 7$ and $\mathrm{f} 8$ fogs, a succession of increases and decreases was observed. During these four fogs, the number concentration reached values much larger than those observed in pre-fog mist. However, the number concentration could also be smaller than in pre-fog mist, as was 

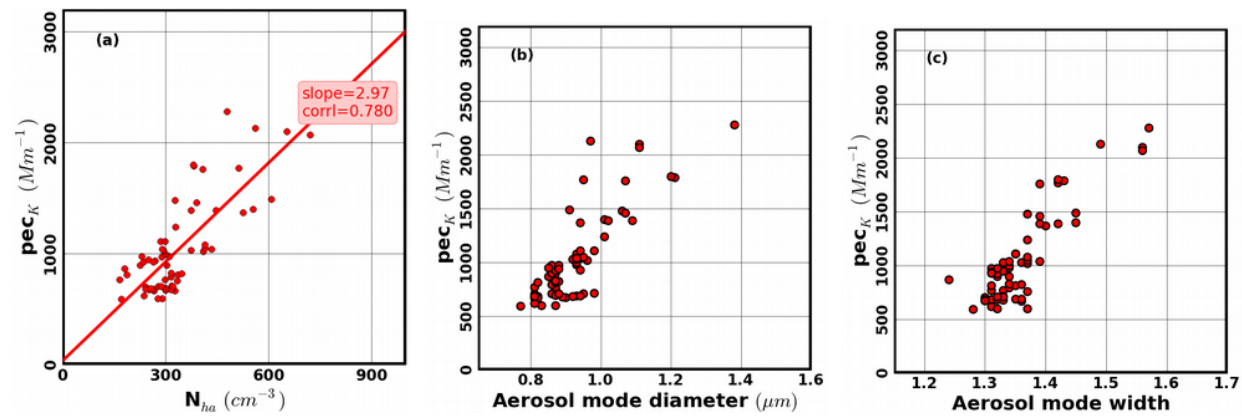

Figure 8. The relationship between the particle extinction coefficient $\left(\mathrm{pec}_{\mathrm{K}}\right)$ directly measured by the DF20+, and the accumulation mode parameters derived from the WELAS: (a) aerosol mode number concentration $\left(N_{\mathrm{ha}}\right)$ (with the linear correlation in red), (b) mode diameter and (c) mode width. Measurements are made during the pre-fog mist events of November 2011.

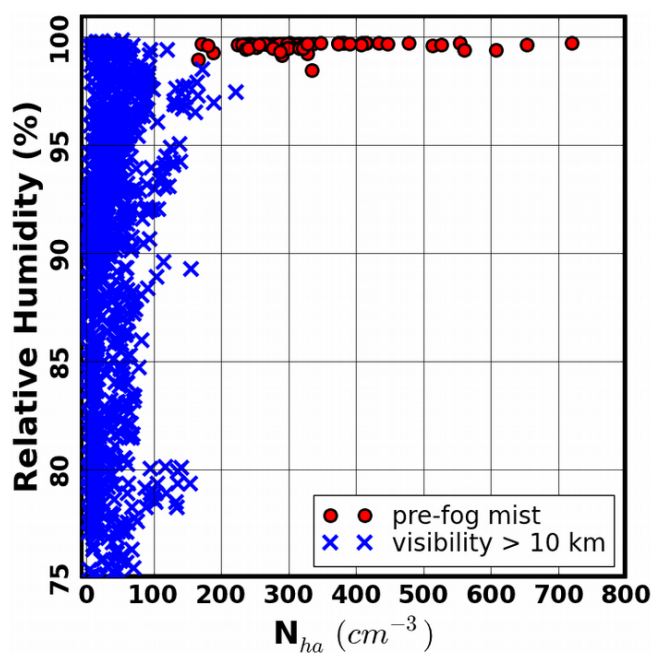

Figure 9. Correlation between relative humidity measured at $2 \mathrm{~m}$ a.g.l. and the hydrated aerosol number concentration for two regimes: visibility $>10 \mathrm{~km}$ and pre-fog mist.

the case during both $\mathrm{f} 1$ and $\mathrm{f} 16 \mathrm{fogs}$, when it decreased down to around $200 \mathrm{~cm}^{-3}$ after the fog onset.

The variability of $N_{\text {ha }}$ increased with the fog duration. While the rate of change of $N_{\text {ha }}$ was mostly between -300 and $300 \mathrm{~cm}^{-3} \mathrm{~h}^{-1}$, the standard deviation was smaller than $15 \%$ when fog lasted $1 \mathrm{~h}$, but it was larger than $50 \%$ when fog lasted more than $12 \mathrm{~h}$. In pre-fog mist, the mean rate of change of $N_{\mathrm{ha}}$ was $100 \mathrm{~cm}^{-3} \mathrm{~h}^{-1}$.

In mist, most aerosols larger than $0.4 \mu \mathrm{m}$ were hydrated. Figure 9 shows that a number concentration larger than $200 \mathrm{~cm}^{-3}$ was observed only in very humid conditions, and the accumulation mode aerosols were on average 10 times more numerous in pre-fog mist than in clear-air (Table 3).

\subsubsection{Hydrated aerosol size}

Such high variability was not observed in the size parameters. On the contrary, a steady increase of the hydrated aerosol size was observed during both the pre-fog mist and the mist-fog transition. Therefore the aerosol extinction coefficient in fog increased because of the average $N_{\text {ha }}$ but also because of the accumulation mode extending to larger sizes.

In pre-fog mist, the accumulation mode diameter increased from 0.8 to more than $1.3 \mu \mathrm{m}$ and simultaneously the mode width increased from 1.3 to more than 1.5 (Fig. $8 \mathrm{~b}$ and c) when $\operatorname{pec}_{\mathrm{K}}$ increased. This observed trend explains that the hydrated aerosol size was too small at a visibility of $\sim 5 \mathrm{~km}$ to be properly measured by WELAS (see Sect. 4.1.1).

In fog, the accumulation mode still widened, with a mean mode width increasing from $1.36 \pm 0.06$ in pre-fog mist to $1.57 \pm 0.10$ in fog. The mode width was frequently larger than 1.50 in fog but rarely in mist. Moreover, the accumulation mode shifted towards larger sizes, with a mean mode diameter increasing from $0.93 \pm 0.11 \mu \mathrm{m}$ in pre-fog mist to $1.14 \pm 0.15 \mu \mathrm{m}$ in fog (Fig. 9). The mode diameter was frequently larger than $1.0 \mu \mathrm{m}$ in fog but rarely in mist. Consequently, a significant proportion of hydrated aerosols was found beyond the diameter of $2.5 \mu \mathrm{m}$ in fog, while they were rarely found in pre-fog mist. Indeed, the transition diameter transition between aerosols and droplets was $4.0 \pm 1.1 \mu \mathrm{m}$ (Fig. 9). According to Chen et al. (2012), such large aerosols are made possible by the large hygroscopic growth factor which sharply increases with RH and can be larger than 3 at RH of $99 \%$ for aerosols of dry diameter of $250-1000 \mathrm{~nm}$. Consistently, Stolaki et al. (2014) showed that the number concentration of aerosols included between 200 and $500 \mathrm{~nm}$ dry diameter, measured by a TSI SMPS particle counter, was of the same order of magnitude as the hydrated aerosols measured by the WELAS.

Hammer et al. (2014b) found a median transition diameter of $2.6 \mu \mathrm{m}$ for the 2012-2013 ParisFog season. We then made computations for our transition diameter and for $2.5 \mu \mathrm{m}$, close to results by Hammer et al. (2014b). The hydrated aerosols larger than $2.5 \mu \mathrm{m}$ were not numerous $\left(35 \pm 30 \mathrm{~cm}^{-3}\right.$, reaching sometimes $\left.100 \mathrm{~cm}^{-3}\right)$, but, as shown in Sect. 3.2, their large size implied a significant contribution to extinction. Measurements presented by Elias 


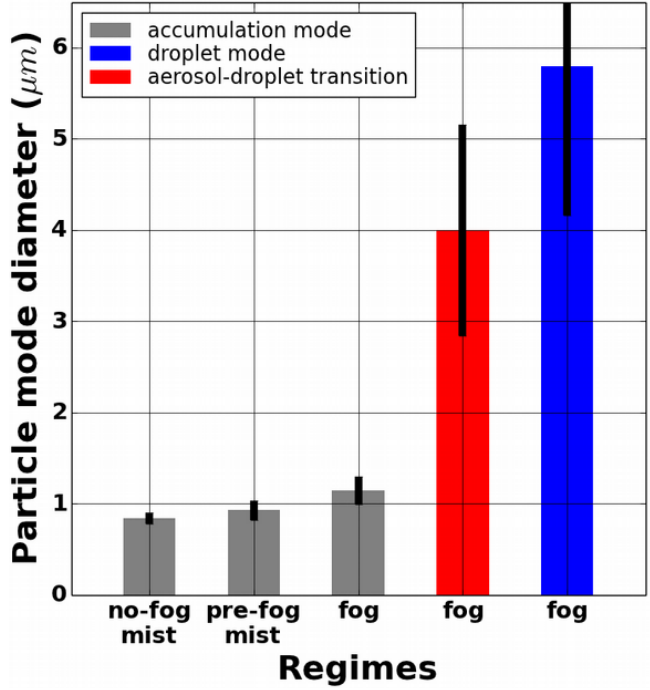

Figure 10. Monthly averages of the particle mode diameter derived from the WELAS data, for different regimes: accumulation mode in mist and in fog (grey), and droplet mode in fog (blue), as well as the aerosol-droplet transition diameter (red). Vertical thick lines depict the standard deviation.

et al. (2009) suggested that the influence of pollution was higher on 18-19 February 2007 than in November 2011: there were more aerosols $\left(6000-15000 \mathrm{~cm}^{-3}\right.$ in fog), and more hydrated aerosols, but they were smaller, with a mode diameter of $0.6 \mu \mathrm{m}$. Eventually, the $25 \%$ aerosol contribution was similar to here.

\subsection{Influence of the fog formation processes}

We used observations to explain the high variability of the hydrated aerosol number concentration. First, we used the aerosol number concentration of all sizes measured by CPC $\left(N_{\mathrm{C}}\right)$, to study the impact of the potential changes of the boundary layer height. Then, we examined the impact of the main fog formation processes.

In relation to aerosols of all sizes, more hydrated aerosols of the accumulation mode were found in fog than in pre-fog mist. With $N_{\mathrm{C}}=5200 \pm 2100 \mathrm{~cm}^{-3}$, around $N_{\mathrm{ha}} / N_{\mathrm{C}}=7 \pm 3 \%$ of aerosols were larger than $0.4 \mu \mathrm{m}$ in pre-fog mist, while the fog ratio was $10 \pm 7 \%$. Variability was large, and significant changes observed during both $\mathrm{f} 1$ and $\mathrm{f} 2 \mathrm{fogs}$ were not caused by potential changes in the mixing boundary layer height. Indeed changes in the mixing boundary layer height are expected to affect all sizes of aerosols similarly, which was not the case on these dates. Figure 11a shows that during the $\mathrm{f} 1 \mathrm{fog}$ and part of the $\mathrm{f} 2 \mathrm{fog}$ (contrasted in terms of $N_{\text {ha }}$ and LWC, Table 3), $N_{\text {ha }}$ slightly increased when $N_{\mathrm{C}}$ also increased, while during the other part of the $\mathrm{f} 2 \mathrm{fog}, N_{\mathrm{ha}}$ varied by a factor of 3 while $N_{\mathrm{C}}$ remained close to $4000 \mathrm{~cm}^{-3}$. However, we observed that there was an influence of the fog formation process on the aerosol number concentration. More hydrated aerosols were found in RAD fogs than in STL fogs, with $600 \pm 350 \mathrm{~cm}^{-3}$ and $360 \pm 140 \mathrm{~cm}^{-3}$, respectively (Table 3 ). Values of fog averages of $N_{\mathrm{ha}}$ between 200 and $650 \mathrm{~cm}^{-3}$ were observed in both STL and RAD fogs, while values larger than $650 \mathrm{~cm}^{-3}$ were encountered only in the RAD fogs (Fig. 11a and Table 3). Similarly, $N_{\mathrm{C}}$ was larger in RAD than in STL fogs, with $6400 \pm 2600$ and $4000 \pm 1400 \mathrm{~cm}^{-3}$, respectively.

Observations showed tendencies in the particle properties which illustrate the aerosol indirect effect on the radiative budget. A large number of aerosols would restrict the droplet growth (e.g. Albrecht, 1989). Consistently, Elias et al. (2012) showed that the droplet size decreased when the droplet number concentration increased for RAD and STL fogs of November 2011. Moreover, a larger number of smaller droplets was correlated with a larger number of aerosols (of all sizes and hydrated) in November 2011, and that occurred in RAD fogs. A consequence of these two factors is the reduction of visibility in RAD fogs, which was enhanced by a third factor: LWC was larger in RAD than in STL fogs. Consequently, visibility in RAD was smaller than in STL by an average of $280 \mathrm{~m}$, or pec $_{\mathrm{K}}$ was larger by $5000 \mathrm{Mm}^{-1}$. Aerosols contributed around $20 \%$ to the RAD-STL extinction difference. Indeed, using an aerosol extinction cross section of $4 \times 10^{-8} \mathrm{~cm}^{2}$, the aerosol extinction coefficient was around $1600 \mathrm{Mm}^{-1}$ in STL and around $2700 \mathrm{Mm}^{-1}$ in RAD. Droplets were therefore responsible for around $4000 \mathrm{Mm}^{-1}$ in the RAD-STL difference. While there is a significant correlation of the fog formation process with $N_{\text {ha }}$, the correlation with the aerosol contribution to extinction was not observed, with $24 \pm 16 \%$ in STL and $19 \pm 14 \%$ in RAD fogs.

Considering that hydrated aerosols are potential condensation nuclei for the formation of fog droplets (Meyer et al., 1980), a large reservoir of nuclei was usually available. Compared to the accumulation mode number, $23 \pm 18 \%$ of droplets were observed in fog. The ratio of the droplet number concentration $\left(\mathrm{N}_{\mathrm{d}}\right)$ over $N_{\text {ha }}$ could be larger than $40 \%$ when $N_{\text {ha }}$ was minimum, as during the RAD f1, STL f16, and RAD f17 fogs. Figure 11b shows that $N_{\text {ha }}$ during the $\mathrm{f} 1 \mathrm{fog}$ is close to the minimum while $N_{\mathrm{d}}$ was the mid range. However, during the $\mathrm{f} 2 \mathrm{fog}$, for similar values of $N_{\mathrm{d}}, N_{\text {ha }}$ was larger than $500 \mathrm{~cm}^{-3}$ and had a tendency to increase with $N_{\mathrm{d}}$.

\section{Conclusions}

The purpose of the research was to estimate the contribution of aerosols to the extinction of visible radiation in mist and fog, and its variability. Comparisons between particle extinction coefficients derived from Mie theory and measured independently showed that the instrument set-up was appropriate to fulfil our objectives.

The size distribution of hydrated aerosols in the accumulation mode, responsible for extinction of visible radiation 

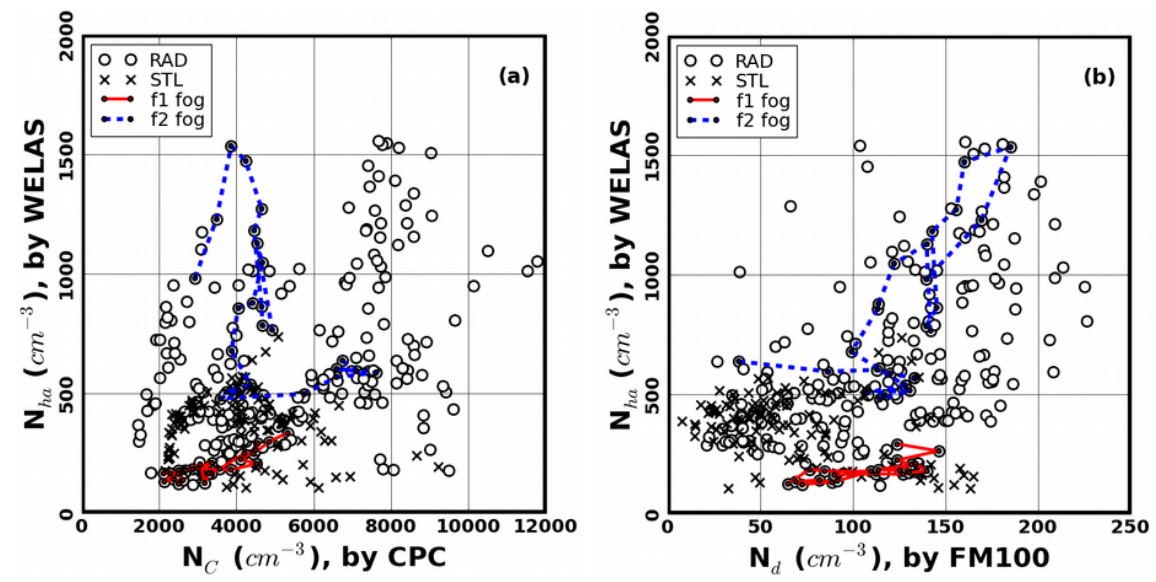

Figure 11. The relationships between several particle number concentrations, marked according to the main formation process, in RAD and STL fogs of November 2011 at SIRTA: (a) the hydrated aerosol number concentration $\left(N_{\text {ha }}\right)$ in function of all aerosol number concentration $\left(N_{\mathrm{C}}\right)$; (b) $N_{\text {ha }}$ in function of the droplet number concentration $\left(N_{\mathrm{d}}\right)$. Two RAD fog events are highlighted in red and blue.

in mist, was measured in ambient conditions. Visibility decreased below $5 \mathrm{~km}$ due to an increase in size of some of the aerosols, due to water intake under high relative humidity conditions. The accumulation mode widened (mode width from 1.3 to 1.5 ) and shifted to larger sizes (mode diameter from 0.8 to $1.3 \mu \mathrm{m}$ ) while visibility decreased from 5 down to a few kilometres. The hydrated aerosol number concentration $\left(N_{\mathrm{ha}}\right)$ increased from 160 to $600 \mathrm{~cm}^{-3}$.

The hydrated aerosols contributed significantly to the extinction of visible radiation in fog. Fog was composed of interstitial non-activated aerosols and of droplets which provided LWC larger than $7 \mathrm{mg} \mathrm{m}^{-3}$. The hydrated nonactivated aerosols continued to grow from mist to fog: the accumulation mode diameter increased to $1.14 \pm 0.15 \mu \mathrm{m}$, and the mode width increased from $1.36 \pm 0.06$ in mist to $1.57 \pm 0.10$ in fog. Moreover, $N_{\text {ha }}$ increased from $330 \pm 100$ to $520 \pm 320 \mathrm{~cm}^{-3}$. Consequently, the hydrated aerosols smaller than $2.5 \mu \mathrm{m}$ contributed an average of $20 \pm 15 \%$ to extinction, with $\pm 8 \%$ uncertainty. The maximum aerosol diameter was found to be variable and often larger than $2.5 \mu \mathrm{m}$, with an average of $4.0 \pm 1.1 \mu \mathrm{m}$. Aerosols larger than $2.5 \mu \mathrm{m}$ were not numerous $\left(35 \pm 30 \mathrm{~cm}^{-3}\right)$ but they contributed a further $6 \pm 7 \%$ to extinction in fog. Visibility lower than $1 \mathrm{~km}$ was caused by LWC greater than $7 \mathrm{mg} \mathrm{m}^{-3}$, but could also be caused by $N_{\text {ha }}$ larger than $800 \mathrm{~cm}^{-3}$. Such a large hydrated aerosol number concentration at SIRTA was observed only in high humidity conditions which also triggered droplet formation.

The particle extinction coefficient in fog can be computed as the sum of an aerosol and a droplet components. The aerosol component can be approximated by $3.5 N_{\text {ha }}$, with $3.5 \times 10^{-8} \mathrm{~cm}^{2}$ being the aerosol extinction cross section estimated in our study. Consequently, observed fog visibility was $380 \pm 320 \mathrm{~m}$ but it would be $530 \pm 490 \mathrm{~m}$ if only droplets were accounted for, with constant LWC (aerosols contribut- ing little to LWC). During fog episodes, the visibility was observed to be larger than $1 \mathrm{~km} 4 \%$ of the time (only in case of STL); however, if only extinction from droplets was to be considered, visibility would have been larger than $1 \mathrm{~km} 17 \%$ of the time.

Part of the large variability observed in $N_{\text {ha }}$ was related to the fog formation process. Observations showed tendencies consistent with the aerosol indirect effect: more aerosols were observed in radiative cooling fogs (RAD) than in STL fogs, and droplets were smaller and more numerous in RAD than in STL fogs. Moreover, LWC was larger in RAD than in STL fogs. Consequently, visibility in RAD was lower than in STL by an average of $280 \mathrm{~m}$. However, the formation process had little influence on the aerosol contribution to fog extinction. Large variability remains unexplained, for example observed $N_{\text {ha }}$ changes were not always correlated with changes of number concentration of droplets or of aerosols of all size.

Radiative transfer computations will be performed in the future. We will quantify the contribution of hydrated aerosols on the radiative budget: impact of mist on radiative cooling, impact of the aerosols on solar heating of the surface layer and on the dissipation time. Microphysical properties of aerosols and droplets are required, but also other properties such as their vertical profile which was also sounded at SIRTA and which is currently analysed. To fully describe the relations between fog and aerosols, we should also study aerosols smaller than $\sim 0.8 \mu \mathrm{m}$ in diameter. No direct measurements were made of such aerosols in ambient conditions, but one method is to convert available TSI SMPS measurements made in the dry state (e.g. Hammer et al., 2014b). New instrumentation may also provide interesting results (Renard et al., 2015a, b). 
Acknowledgements. Authors are very grateful to all SIRTA operators, instrument owners and database managers. Study was supported by the RAPID dispositive of the French organizations DGA/DGCIS, in the framework of the PreViBOSS project. We acknowledge AERONET for providing column aerosol properties. We are very grateful to Stavroula Stolaki for helping in the editing process. C. R. Hoyle was funded by the Swiss National Science Foundation (SNSF) (grant number 200021 140663).

Edited by: M. Petters

\section{References}

Adams, P. J., Seinfeld, J. H., and Koch, D. M.: Global concentration of tropospheric sulfate, nitrate, and ammonium aerosol simulated in a general circulate model, J. Geophys. Res., 104, 13791-13823, 1999.

Ahmed, R., Dey, S., and Mohan, M.: A study to improve night time fog detection in the Indo-Gangetic Basin using satellite data and to investigate the connection to aerosols, Met. Apps., doi:10.1002/met.1468, online first, 2014.

Albrecht B.: Aerosols, cloud microphysics, and fractional cloudiness, Science, 245, 1227-1230, 1989.

Allan, J. D., Baumgardner, D., Raga, G. B., Mayol-Bracero, O. L., Morales-García, F., García-García, F., Montero-Martínez, G., Borrmann, S., Schneider, J., Mertes, S., Walter, S., Gysel, M., Dusek, U., Frank, G. P., and Krämer, M.: Clouds and aerosols in Puerto Rico - a new evaluation, Atmos. Chem. Phys., 8, 1293 1309, doi:10.5194/acp-8-1293-2008, 2008.

Anderson, T., Charlson, R. J., Schwartz, S. E., Knutti, R., Boucher, O., Rodhe, H., and Heintzenberg, J.: Climate forcing by aerosols: A hazy picture, Science, 300, 1103-1104, 2003.

Bergot, T., Hae elin, M., Musson-Genon, L., Tardif , R., Colomb, M., Boitel, C., Bouhours, G., Bourriane, T., Carrer, D., Challet, J., Chazette, P., Drobinski, P., Dupont, E., Dupont, J.-C., Elias, T., Fesquet, C., Garrouste, O., Gomes, L., Guérin, A., Lapouge, F., Lefranc, Y., Legain, D., Morange, P., Pietras, C., Plana-Fattori, A., Protat, A., Rangognio, J., Raut, J.-C., Remy, S., Richard, D., Romand, B., and Zhang, X.: ParisFog: des chercheurs dans le brouillard, La Météorologie, 8, 48-58, doi:10.4267/2042/19175, 2008.

Berkowitz, C. M., Berg, L. K., Yu, X. Y., Alexander, M. L., Laskin, A., Zaveri R. A., Jobson B. T., Andrews, E., and Ogren, J. A.: The Influence of Fog and Airmass History on Aerosol Optical, Physical and Chemical Properties at Pt. Reyes National Seashore, Atmos. Environ., 45, 2259-2568, doi:10.1016/j.atmosenv.2011.02.016, 2011.

Bohren, C. F. and Huffman, D. R.: Absorption and Scattering of Light by Small Particles. John Wiley, New York, 1983.

Boucher, O., Randall, D., Artaxo, P., Bretherton, C., Feingold, G., Forster, P., Kerminen, V.-M., Kondo, Y., Liao, H., Lohmann, U., Rasch, P., Satheesh, S. K., Sherwood, S., Stevens, B., and Zhang, X. Y.: Clouds and Aerosols. In: Climate Change 2013: The Physical Science Basis. Contribution of Working Group I to the Fifth Assessment Report of the Intergovernmental Panel on Climate Change, edited by: Stocker, T. F., Qin, D., Plattner, G.-K., Tignor, M., Allen, S. K., Boschung, J., Nauels, A., Xia, Y., Bex,
V., and Midgley, P. M., Cambridge University Press, Cambridge, United Kingdom and New York, NY, USA, 2013.

Burkard, R., Eugster, W., Wrzesinsky, T., and Klemm, O.: Vertical divergence of fogwater fluxes above a spruce forest, Atmos. Res., 64, 133-145, 2002.

Burnet, F., Gomes, L., Haeffelin, M., Dupont, J. C., and Elias, T.: Analysis of the microphysical structures of fog during the ParisFog Project, in: Proceedings of the 16th international conference of clouds and precipitation (ICCP), Leipzig, Germany, 30 July-3 August, p. 582, 2012.

Chen, J., Zhao, C. S., Ma, N., Liu, P. F., Göbel, T., Hallbauer, E., Deng, Z. Z., Ran, L., Xu, W. Y., Liang, Z., Liu, H. J., Yan, P., Zhou, X. J., and Wiedensohler, A.: A parameterization of low visibilities for hazy days in the North China Plain, Atmos. Chem. Phys., 12, 4935-4950, doi:10.5194/acp-12-4935-2012, 2012.

Clark, P. A., Harcourt, S. A., Macpherson, B., Mathison, C. T., Cusack, S., and Naylor, M.: Prediction of visibility and aerosol within the operational Met Office Unified Model. I: Model formulation and variational assimilation, Q. J. R. Meteorol. Soc., 134, 1801-1816, 2008.

Crosby, J. D.: Visibility sensor accuracy: what's realistic?, in: $12^{\text {th }}$ Symposium on Meteorological Observations and Instrumentation, Long Beach, CA, 15.5, 13 February 2003.

Dupont, J.-C., Haeffelin, M., Elias, T., and Stolaki, S.: Analysis of dynamical and thermal processes driving fog and quasi-fog life cycles using the 2010-2013 ParisFog dataset, Pure Appl. Geophys., accepted, 2015.

Eldridge, R. G.: Haze and fog distributions, J. Atmos. Sci., 23, 605613, 1966.

Elias, T., Haeffelin, M., Drobinski, P., Gomes, L., Rangognio, J., Bergot, T., Chazette, P., Raut, J.-C., and Colomb, M.: Particulate contribution to extinction of visible radiation: pollution, haze, and fog, Atmos. Res., 92, 443-454, 2009.

Elias, T., Jolivet, D., Dupont, J.-C., Haeffelin, M., and Burnet, F.: Preliminary results of the PreViBOSS project: description of the fog life cycle by ground-based and satellite observation, in: Proc. SPIE 8534, Remote Sensing of Clouds and the Atmosphere XVII, and Lidar Technologies, Techniques, and Measurements for Atmospheric Remote Sensing VIII, 853406 (1 November 2012), edited by: Kassianov, E. I., Comeron, A., Picard, R. H., Schäfer, K., Singh, U. N., and Pappalardo, G., doi:10.1117/12.974709, 2012.

Frank, G., Martinsson, B. G., Cederfelt, S., Berg, O.H., Swietlick, E., Wendisch, M., Yuskiewicz, B., Heintzenberg, J., Wiedensohler, A., Orsini, D., Stratmann, F., Laj, P., and Ricci, L.: Droplet formation and growth in polluted fogs, Beitr. Atmos. Phys., 71, 65-85, 1998.

Gultepe, I., Müller, M. D., and Boybeyi, Z.: A new visibility parameterization for warm-fog applications in numerical weather prediction models, J. Appl. Meteor. Climatol., 45, 1469-1480, 2006.

Haeffelin, M., Barthès, L., Bock, O., Boitel, C., Bony, S., Bouniol, D., Chepfer, H., Chiriaco, M., Cuesta, J., Delanoë, J., Drobinski, P., Dufresne, J.-L., Flamant, C., Grall, M., Hodzic, A., Hourdin, F., Lapouge, F., Lemaître, Y., Mathieu, A., Morille, Y., Naud, C., Noël, V., O'Hirok, W., Pelon, J., Pietras, C., Protat, A., Romand, B., Scialom, G., and Vautard, R.: SIRTA, a ground-based atmospheric observatory for cloud and aerosol research, Ann. Geophys., 23, 253-275, doi:10.5194/angeo-23-253-2005, 2005. 
Haeffelin, M., Bergot, T., Elias, T., Tardif, R., Carrer, D., Chazette, P., Colomb, M., Drobinski, P., Dupont, E., Dupont, J.-C., Gomes, L., Musson-Genon L., Pietras, C., Plana-Fattori, A., Protat, A., Rangognio, J., Raut, J.-C., Rémy, S., Richard, D., Sciare, J., and Zhang, X.: PARISFOG: Shedding New Light on Fog Physical Processes, Bull. Am. Meteorol. Soc., 91, 767-783, doi:10.1175/2009BAMS2671.1, 2010.

Haeffelin, M., Dupont, J. C., Boyouk, N., Baumgardner, D., Gomes, L., Roberts, G., and Elias, T.: A Comparative Study of Radiation Fog and Quasi-Fog Formation Processes during the ParisFog Field Experiment 2007, Pure Appl. Geophys., 170, 2283-2303, 2013.

Hammer, E., Bukowiecki, N., Gysel, M., Jurányi, Z., Hoyle, C. R., Vogt, R., Baltensperger, U., and Weingartner, E.: Investigation of the effective peak supersaturation for liquid-phase clouds at the high-alpine site Jungfraujoch, Switzerland (3580 m a.s.l.), Atmos. Chem. Phys., 14, 1123-1139, doi:10.5194/acp-14-11232014, 2014a.

Hammer, E., Gysel, M., Roberts, G. C., Elias, T., Hofer, J., Hoyle, C. R., Bukowiecki, N., Dupont, J.-C., Burnet, F., Baltensperger, U., and Weingartner, E.: Size-dependent particle activation properties in fog during the ParisFog 2012/13 field campaign, Atmos. Chem. Phys., 14, 10517-10533, doi:10.5194/acp14-10517-2014, 2014b.

Heim, M., Mullins, B. J., Umhauer, H., and Kasper, G.: Performance evaluation of three optical particle counters with an efficient "multimodal" calibration method, J. Aerosol Sci., 39, 1019-1031, 2008.

Heintzenberg, J.: Properties of the Log-Normal Particle Size Distribution, Aerosol Sci. Technol., 21, 46-48, doi:10.1080/02786829408959695, 1994.

Heintzenberg, J., Wendisch, M., Yuskiewicz, B., Orsini, D., Wiedensohler, A., Stratmann, F., Frank, G., Martinsson, B. G., Schell, D., Fuzzi, S., and Orsi, G.: Characteristics of haze, mist and fog, Beitr. Atmos. Phys., 71, 21-31, 1998.

Hess, M., Koepke, P., and Schult, I.: Optical properties of aerosols and clouds: the software package OPAC, Bull. Am. Meteorol. Soc., 79, 831-844, 1998.

Hoag, K. J., Collett Jr., J. L., and Pandis, S. N.: The influence of drop size-dependent fog chemistry on aerosol processing by San Joaquin Valley fogs, Atmos. Environ., 33, 4817-4832, 1999.

Holben, B. N., Eck, T. F., Slutsker, I., Tanré, D., Buis, J. P., Setzer, A., Vermote, E., Reagan, J. A., Kaufman, Y. J.,Nakajima, T., Lavenu, F., Jankowiak, I., and Smirnov, A.: AERONET - a federated instrument network and data archive for aerosol characterization, Remote Sens. Environ., 66, 1-16, 1998.

Jiusto, J. E.: Fog structure, in: Clouds: their formation, optical properties and effects, edited by: Hobbs, P. V., and Deepak, A., Academic Press, New York, 187-239, 1981.

Köhler, H.: The nucleus in and the growth of hygroscopic droplets, Trans. Faraday Soc., 32, 1152-1161, 1936.

Kunkel, B. A.: Parameterization of droplet terminal velocity and extinction coefficient in fog models, J. Clim. Appl. Meteorol., 23, 34-41, 1984.

Menut, L., Mailler, S., Dupont, J.-C., Haeffelin, M., and Elias, T.: Predictability of the meteorological conditions favorable to radiative fog formation during the 2011 ParisFog campaign, Bound.-Lay. Meteorol., 150, 277-297, doi:10.1007/s10546-0139875-1, 2013.
Meyer, M. B. and Lala, G. G.: Climatological aspects of radiation fog occurrence at Albany, New York, J. Climate, 3, 577-586, 1990.

Meyer, M. B., Jiusto, J. E., and Lala, G. G.: Measurements of visual range and radiation-fog (haze) microphysics, J. Atmos. Sci., 37, 622-629, 1980.

Mukund, V., Singh, D. K., Ponnulakshmi V. K., Subramanian, G., and Sreenivas, K. R.: Field and laboratory experiments on aerosol-induced cooling in the nocturnal boundary layer, Q. J. R. Meteorol. Soc., 140, 151-169, doi:10.1002/qj.2113, 2014.

National Oceanic and Atmospheric Administration: Surface weather observations and reports, Federal Meteorological Handbook, vol. 1, Washington, DC, 94 pp., 1995.

Noone, K. J., Ogren, J. A., Hallberg, A., Heintzenberg, J., Ström, J., Hansson, H. C., Svenningsson, B., Wiedensohler, A., Fuzzi, S., Facchini, M. C., Arends, B. G., and Berner, A.: Changes in aerosol size- and phase distributions due to physical and chemical processes in fog, Tellus, 44B, 489-504, 1992.

Pandis, S. N. and Seinfeld, J. H.: The smog-fog-smog cycle and acid deposition, J. Geophys. Res., 95, 18489-18500, 1990.

Pearce, F.: Back to the days of deadly smogs, New Sci., 1850, 25 28, 1992.

Quan, J., Zhang, Q., He, H., Liu, J., Huang, M., and Jin, H.: Analysis of the formation of fog and haze in North China Plain (NCP), Atmos. Chem. Phys., 11, 8205-8214, doi:10.5194/acp-11-82052011, 2011.

Renard, J.-B., Dulac, F., Berthet, G., Lurton, T., Vignelles, D., Jégou, F., Tonnelier, T., Thaury, C., Jeannot, M., Couté, B., Akiki, R., Mineau, J.-L., Verdier, N., Mallet, M., Gensdarmes, F., Charpentier, P., Mesmin, S., Duverger, V., Dupont, J.-C., Elias, T., Crenn, V., Sciare, J., Giacomoni, J., Gobbi, M., Hamonou, E., Olafsson, H., Dagsson-Waldhauserova, P., Camy-Peyret, C., Mazel, C., Décamps, T., Piringer, M., Surcin, J., and Daugeron, D.: LOAC: a small aerosol optical counter/sizer for ground-based and balloon measurements of the size distribution and nature of atmospheric particles - Part 1: Principle of measurements and instrument evaluation, Atmos. Meas. Tech. Discuss., 8, 1203 1259, doi:10.5194/amtd-8-1203-2015, 2015.

Renard, J.-B., Dulac, F., Berthet, G., Lurton, T., Vignelle, D., Jégou, F., Tonnelier, T., Thaury, C., Jeannot, M., Couté, B., Akiki, R., Mineau, J.-L., Verdier, N., Mallet, M., Gensdarmes, F., Charpentier, P., Mesmin, S., Duverger, V., Dupont, J.-C., Elias, T., Crenn, V., Sciare, J., Giacomoni, J., Gobbi, M., Hamonou, E., Olafsson, H., Dagsson-Waldhauserova, P., Camy-Peyret, C., Mazel, C., Décamps, T., Piringer, M., Surcin, J., and Daugeron, D.: LOAC: a small aerosol optical counter/sizer for ground-based and balloon measurements of the size distribution and nature of atmospheric particles - Part 2: First results from balloon and unmanned aerial vehicle flights, Atmos. Meas. Tech. Discuss., 8, 1261-1299, doi:10.5194/amtd-8-1261-2015, 2015.

Rosenfeld, J.: Cars vs. the weather, A century of progress, Weatherwise, 49, 14-23, 1996.

Seinfeld, J. H. and Pandis, S. N.: Atmospheric Chemistry and Physics: From Air Pollution to Climate Change, John Wiley, New York, 1360 pp., 1998.

Shettle, E. P. and Fenn, R. W.: Models for the aerosols of the lower atmosphere and the effects of humidity variations on their optical properties, AFGL-TR-79-0214, Environmental Research Paper 
Air Force Geophysics Lab., Hanscom AFB, MA, Optical Physics Div., 94 pp., 1979.

Spiegel, J. K., Zieger, P., Bukowiecki, N., Hammer, E., Weingartner, E., and Eugster, W.: Evaluating the capabilities and uncertainties of droplet measurements for the fog droplet spectrometer (FM-100), Atmos. Meas. Tech., 5, 2237-2260, doi:10.5194/amt5-2237-2012, 2012.

Stolaki, S., Haeffelin, M., Lac, C., Dupont, J.-C., Elias, T., and Masson, V.: Influence of aerosols on the life cycle of a radiation fog event. A numerical and observational study, Atmos. Res., 151, 146-161, doi:10.1016/j.atmosres.2014.04.013, 2014.

Tardif, R. and Rasmussen, R. M.: Event-based climatology and typology of fog in the New York City region, J. Appl. Meteor. Climatol., 46, 1141-1168, 2007.

van Schalkwyk, L. and Dyson, L. L.: Climatological Characteristics of Fog at Cape Town International Airport, Weather Forecast., 28, 631-646, doi:10.1175/WAF-D-12-00028.1, 2013.
Wendisch, M.: A quantitative comparison of ground-based FSSP and PVM measurements, J. Atmos. Sci. Technol., 15, 887-900, 1998.

Wendisch, M., Mertes, S., Heintzenberg, J., Wiedensohler, A., Schell, D., Wobrock, W., Frank, G., Martinsson, B. G., Fuzzi, S., Orsi, G., Kos, G., and Berner, A.: Drop size distribution and LWC in Po Valley fog, Beitr. Atmos. Phys., 71, 87-100, 1998.

Whitby, K. T.: The physical characteristics of sulfur aerosols, Atmos. Environ., 12, 135-159, 1978.

Winkler, P.: The growth of atmospheric aerosol particles with relative humidity, Phys. Scr., 37, 223-230, 1988.

Yuskiewicz, B., Orsini, D., Stratmann, F., Wendisch, M., Wiedensohler, A., Heintzenberg, J., Martinsson, B. G., Frank, G., Wobrock, W., and Schell, D.: Changes in submicrometer particle distributions and light scattering during haze and fog events in a highly polluted environment, Beitr. Atmos. Phys., 71, 33-45, 1998. 